\title{
Obatoclax induces Atg7-dependent autophagy independent of beclin-1 and BAX/BAK
}

\author{
F McCoy ${ }^{1}$, J Hurwitz ${ }^{1}$, N McTavish ${ }^{1}$, I Paul ${ }^{1}$, C Barnes ${ }^{2}$, B O’Hagan² ${ }^{2}$ K Odrzywol ${ }^{1}$, J Murray ${ }^{1}$, D Longley ${ }^{1}$, G McKerr ${ }^{2}$ and DA Fennell ${ }^{\star 1}$
}

Direct pharmacological targeting of the anti-apoptotic B-cell lymphoma-2 (BCL-2) family is an attractive therapeutic strategy for treating cancer. Obatoclax is a pan-BCL-2 family inhibitor currently in clinical development. Here we show that, although obatoclax can induce mitochondrial apoptosis dependent on BCL-2 associated $x$ protein/BCL-2 antagonist killer (BAX/BAK) consistent with its on-target pharmacodynamics, simultaneous silencing of both BAX and BAK did not abolish acute toxicity or loss of clonogenicity. This is despite complete inhibition of apoptosis. Obatoclax dramatically reduced viability without inducing loss of plasma membrane integrity. This was associated with rapid processing of light chain-3 (LC3) and reduction of S6 kinase phosphorylation, consistent with autophagy. Dramatic ultrastructural vacuolation, not typical of autophagy, was also induced. Silencing of beclin-1 failed to prevent LC3 processing, whereas knockout of autophagy-related (Atg)7 abolished LC3 processing but failed to prevent obatoclax-induced loss of clonogenicity or ultrastructural changes. siRNA silencing of Atg7 in BAX/BAK knockout mouse embryonic fibroblasts did not prevent obatoclax-induced loss of viability. Cells selected for obatoclax resistance evaded apoptosis independent of changes in BCL-2 family expression and displayed reduced LC3 processing. In summary, obatoclax exhibits BAX- and BAK-dependent and -independent mechanisms of toxicity and activation of autophagy. Mechanisms other than autophagy and apoptosis are blocked in obatoclax resistant cells and contribute significantly to obatoclax's anticancer efficacy.

Cell Death and Disease (2010) 1, e108; doi:10.1038/cddis.2010.86; published online 16 December 2010

Subject Category: Cancer

The ability of cancer cells to evade apoptosis is a hallmark of both cancer and drug resistance. ${ }^{1}$ Activation of the intrinsic apoptosis pathway requires mitochondrial outer membrane permeabilization (MOMP) mediated by the pro-apoptotic multi-domain B-cell lymphoma-2 (BCL-2) family proteins $B C L-2$ associated $x$ protein $(B A X)$ and $B C L-2$ antagonist killer $(B A K){ }^{2}$ This results in adenosine triphosphate (dATP)/ cytochrome c/apaf-1-dependent activation of caspase 9 leading to executioner caspase $3 / 7$ activation and cleavage of numerous substrates including poly ADP ribose polymerase (PARP) to mediate apoptosis. ${ }^{3-7}$ BAX and BAK are inhibited by anti-apoptotic BCL-2 family proteins, which include $B C L-2, B C L-2$ regulated gene long isoform (BCL-xl), BCL-2 like protein 2 (BCL-w), A1 and myeloid cell leukemia-1 (MCL-1). These are in turn antagonized by a subset of proapoptotic proteins harboring a single 16-amino acid alpha helical amphipathic BCL-2 homology domain 3 (BH3). ${ }^{8,9}$ The pro-survival $B C L-2$ family proteins $M C L-1$ and $B C L-x I$ have been shown to be among the most commonly amplified oncogenes in the cancer genome, ${ }^{10}$ as a result the BCL-2 family of proteins represent attractive targets for therapies in many cancers. ${ }^{11}$ Accordingly, recently identified small molecules that mimic BH3-only proteins constitute a new class of potentially important targeted therapeutics. ${ }^{12}$ One such small molecule is ABT-737 (and its orally active analog ABT-263), ${ }^{13}$ which were discovered using a nuclear magnetic resonancebased approach to determine structure activity relationships. ABT-737 exhibits very high-affinity binding $\left(\mathrm{K}_{i} \leq 1 \mathrm{nM}\right)$ for $B C L-2, B C L-x l$ and BCL-w but not MCL-1. Consequently, high expression of MCL-1 has been observed as a mechanism of resistance to $\mathrm{ABT}-737$. $^{14,15}$

Obatoclax is a pan-BCL-2 inhibitor discovered using a protein-protein interaction screen of natural compound libraries ${ }^{16}$ and in contrast to ABT-737 binds all pro-survival BCL-2 family members (including MCL-1), although with a much lower affinity $\left(\mathrm{K}_{\mathrm{i}} \sim 1-5 \mu \mathrm{M}\right) .{ }^{17}$ Obatoclax displaces $\mathrm{BAK} / \mathrm{MCL}-1$ and $\mathrm{BCL}-2$ interacting mediator of cell death (BIM)/MCL-1 complexes $^{18-23}$ and in so doing activates mitochondrial apoptosis. Recent reports have implicated off-target activities of obatoclax, possibly independent of BAX

\footnotetext{
${ }^{1}$ Centre for Cancer Research and Cell Biology, Queen's University Belfast, Belfast, Northern Ireland, UK and ${ }^{2} \mathrm{FEI}$ Centre for Advanced Imaging, University of Ulster, Ulster, Northern Ireland, UK

${ }^{*}$ Corresponding author: DA Fennell, Centre for Cancer Research and Cell Biology, Queen's University Belfast, 97 Lisburn Road, Belfast, Northern Ireland BT9 7BL, UK. Tel: + 44289097 2760; Fax: + 44289097 2755; E-mail: d.fennell @qub.ac.uk

Keywords: obatoclax; apoptosis; autophagy; BAX/BAK; atg7

Abbreviations: 3-MA, 3-methyladenine; Atg, Autophagy related; ATP, Adenosine triphosphate; BAK, BCL-2 antagonist killer; BAX, BCL-2 associated x protein; BID, BCL-2 interacting domain death agonist; BIM, BCL-2 interacting mediator of cell death; BCL-2, B-cell lymphoma-2; BCL-w, BCL-2 like protein 2; BCL-xl, BCL-2 regulated gene, long isoform; DKO, Double knockout; ENU, N-Nitroso-N-ethylurea; ER, Endoplasmic reticulum; LC3, Light chain-3; MCL-1, Myeloid cell leukemia-1; MEFs, Mouse embryonic fibroblasts; MIB, Mitochondrial isolation buffer; MRB, Mitochondrial respiration buffer; MOMP, Mitochondrial outer membrane permeabilization; NSCLC, Nonsmall cell lung cancer; PARP, Poly (ADP-ribose) polymerase; SCLC, Small cell lung cancer; SMAC, Second mitochondrial derived activator of caspases; TRAIL, Tumor necrosis factor-related apoptosis-inducing ligand

Received 20.7.10; revised 11.10.10; accepted 28.10.10; Edited by A Stephanou
} 
and BAK, in different preclinical cancer models. ${ }^{24}$ These offtarget activities include autophagy, ${ }^{25-28}$ however, the impact of autophagy on obatoclax-induced cytotoxicity is unclear as the pharmacodynamics have not been explored in detail. Here, we show that obatoclax induces autophagy-related (Atg)7 but not beclin-1-dependent autophagy in the presence or absence of BAX and BAK, and that this activity is suppressed in obatoclax resistant cells.

\section{Results}

Obatoclax-induced apoptosis requires $\mathrm{BAX}$ and BAK. Obatoclax has previously been shown to exhibit on-target activity, dissociating BAK from MCL-1. ${ }^{18-22}$ We also observed this activity in $\mathrm{H} 460$ non-small-cell lung cancer (NSCLC) cells (Figure 1a). This was associated with induction of mitochondrial apoptosis, as evidenced by BAK conformation change and mitochondrial membrane permeabilization associated with BAK activation, release of second mitochondrial derived activator of caspases (SMAC) and cleavage of PARP (Figures 1b-d). We next examined the requirement for BAX and BAK expression for obatoclax-induced apoptosis using H460 NSCLC cells stably transfected with short hairpin RNAs simultaneously targeting both BAX and BAK (H460 $\left.{ }^{\text {shBAX/BAK }}\right)$. Obatoclax-induced apoptosis was significantly reduced in $\mathrm{H} 460^{\text {shBAX/BAK }}$ cells relative to non-targeting transfected control cells $\left(\mathrm{H} 460^{\text {shNT/NT }}\right)$ as assessed by caspase 9, caspase 3 and PARP cleavage (Figure 2a). $\mathrm{H} 460^{\text {shBAX/BAK }}$ cells failed to undergo mitochondrial apoptosis in response to staurosporine and cell permeable proapoptotic peptides corresponding to the $\mathrm{BH} 3$ domain of activating $\mathrm{BH} 3-$ only protein $\mathrm{BCL}-2$ interacting domain death agonist (BID) (data not shown). BAX/BAK-dependent apoptosis induction by obatoclax was further confirmed in BAX and BAK double-knockout mouse embryonic fibroblasts (DKO MEFs) compared with wild-type (WT) controls (Figure 2b).

Loss of BAX/BAK fails to rescue cells following obatoclax. To further assess the requirement for $B A X$ and BAK in obatoclax-induced toxicity, we looked at both its short- and long-term effects on the viability and clonogenic survival of $\mathrm{H} 460 \mathrm{NSCLC}$ cells stably transfected with shRNAs targeting BAX and BAK $\left(\mathrm{H} 460^{\text {shBAX/BAK })}\right)$, and BAX/BAK DKO MEFs. In contrast to the requirement for $B A X$ and BAK in induction of apoptosis, obatoclax was very

a 500nM Obx exposure (hrs)
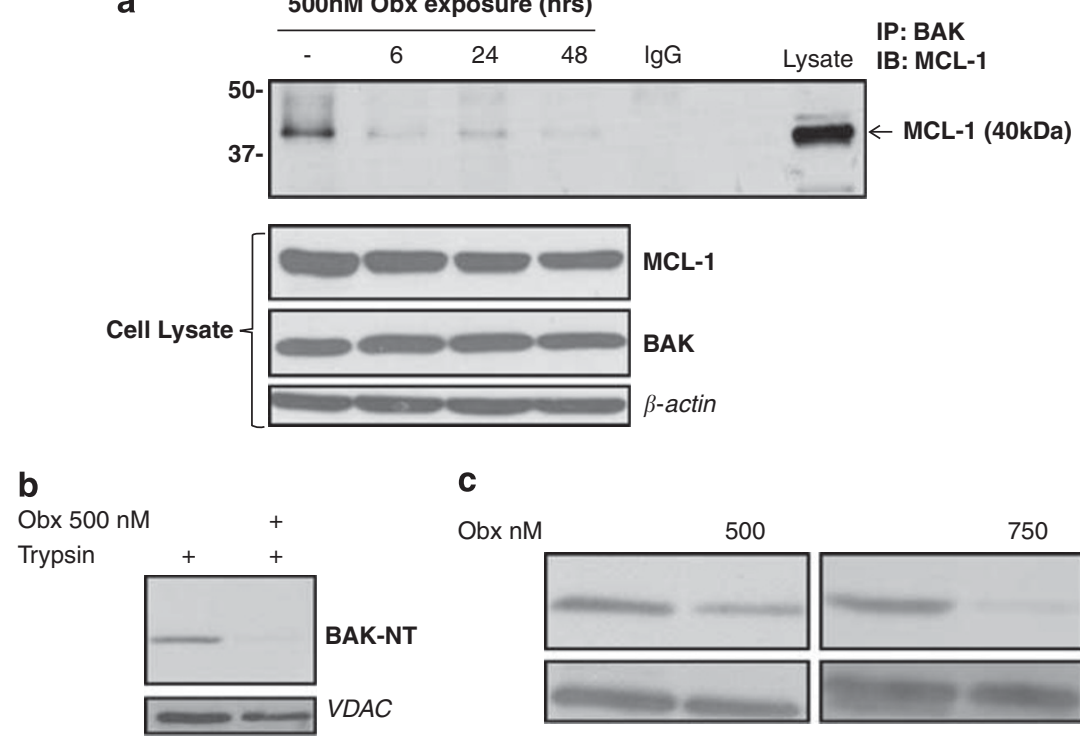

c

Obx nM

500
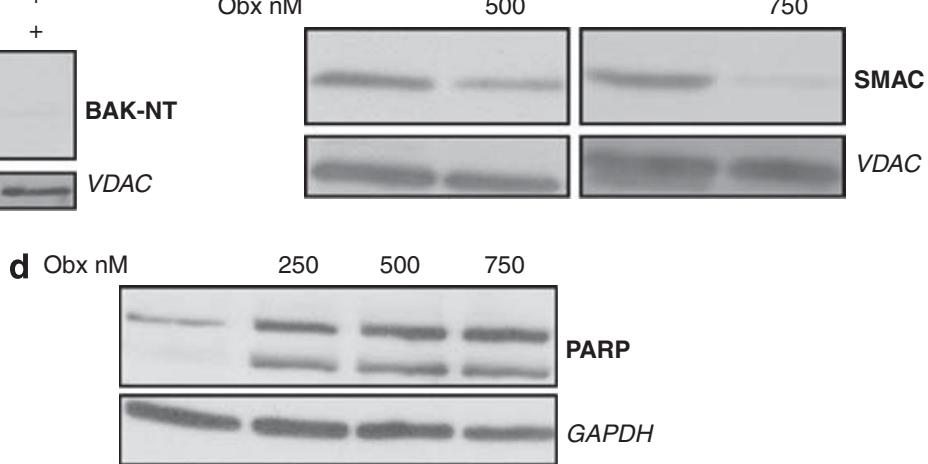

Figure 1 Obatoclax exhibits on-target activity associated with mitochondrial apoptosis. (a) Obatoclax disrupts BAK/MCL-1 complex in H460 NSCLC cells. H460 cells were incubated with obatoclax for 6,24 and $48 \mathrm{~h}$, after which time total cell lysate was subjected to immunoprecipitation with anti BAK antibody. Immunoprecipitates were analyzed for MCL-1 levels by SDS-PAGE. Whole-cell lysates were also probed for BAK and MCL-1 levels by SDS-PAGE. $\beta$-Actin was used as a loading control. (b) Obatoclax induces BAK activation in H1975 NSCLC cells. $\mathrm{H} 1975$ cells were treated with $500 \mathrm{nM}$ obatoclax for $48 \mathrm{~h}$. Mitochondria were then isolated and incubated with trypsin $(125 \mu \mathrm{g} / \mathrm{ml})$ and analyzed for BAK by SDS-PAGE and immunoblotting with an antibody directed against amino acids $23-37$ of BAK (BAK-NT). VDAC was used as a mitochondrial-specific loading control. (c) Obatoclax induces mitochondrial outer membrane permeabilization in $\mathrm{H} 1975$ cells. $\mathrm{H} 1975$ cells were treated with 500 or $750 \mathrm{nM}$ obatoclax for $48 \mathrm{~h}$. Mitochondria were then isolated and probed for SMAC levels by SDS-PAGE. VDAC was used as a mitochondrial-specific loading control. (d) Obatoclax induces PARP cleavage in H1975 cells. H1975 cells were treated with indicated doses of obatoclax for $48 \mathrm{~h}$. The level of PARP cleavage was determined by SDS-PAGE. GAPDH was used as a loading control 

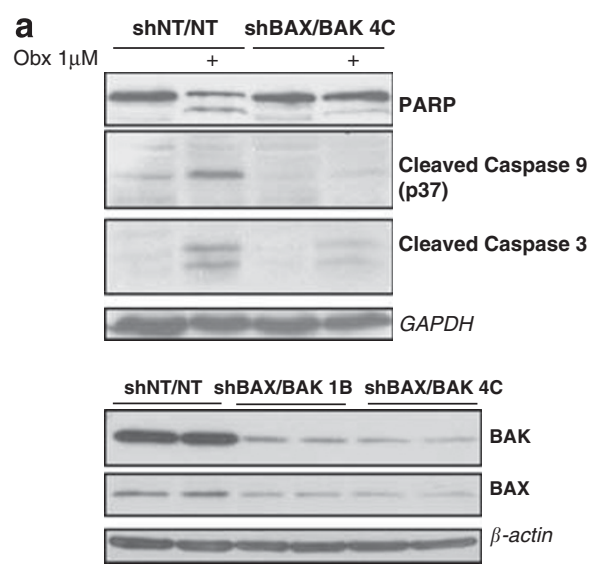

C
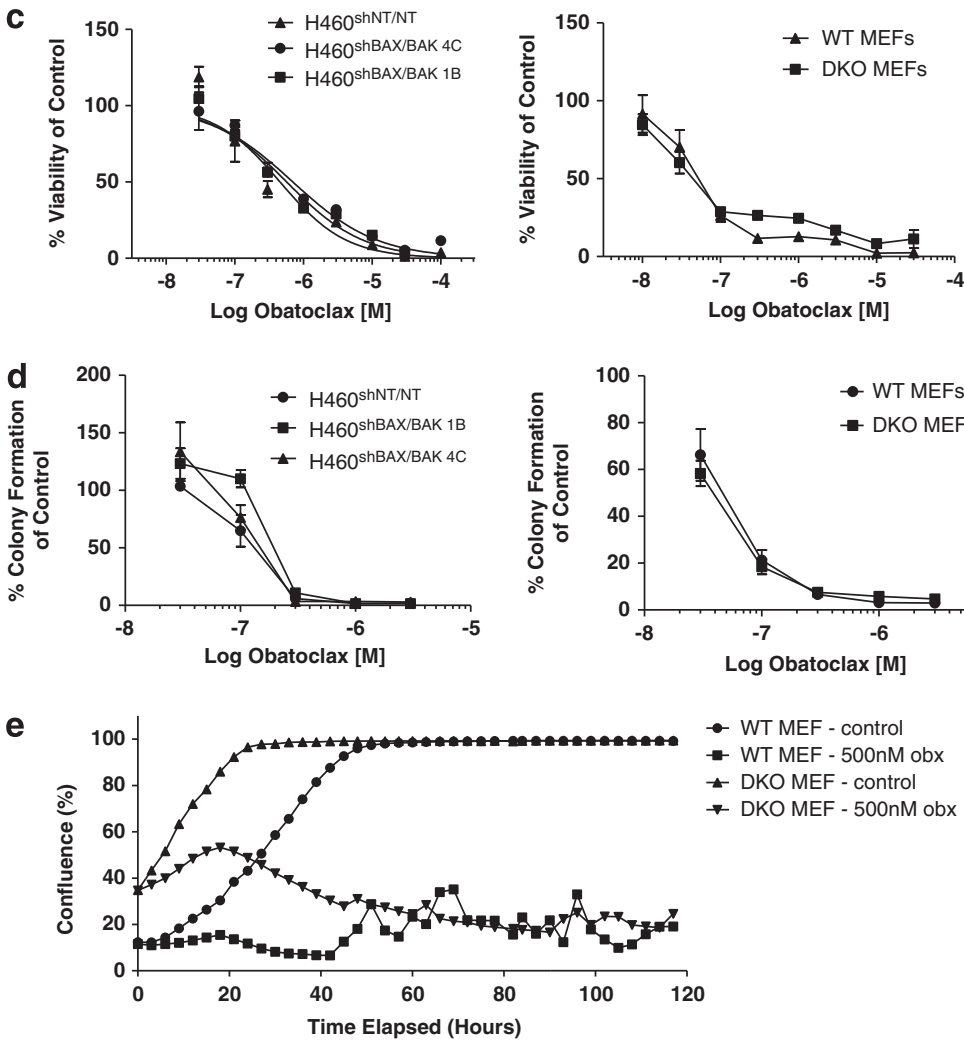

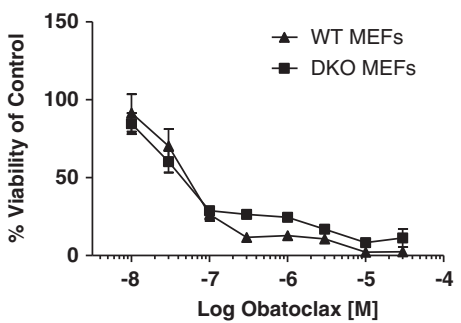

b
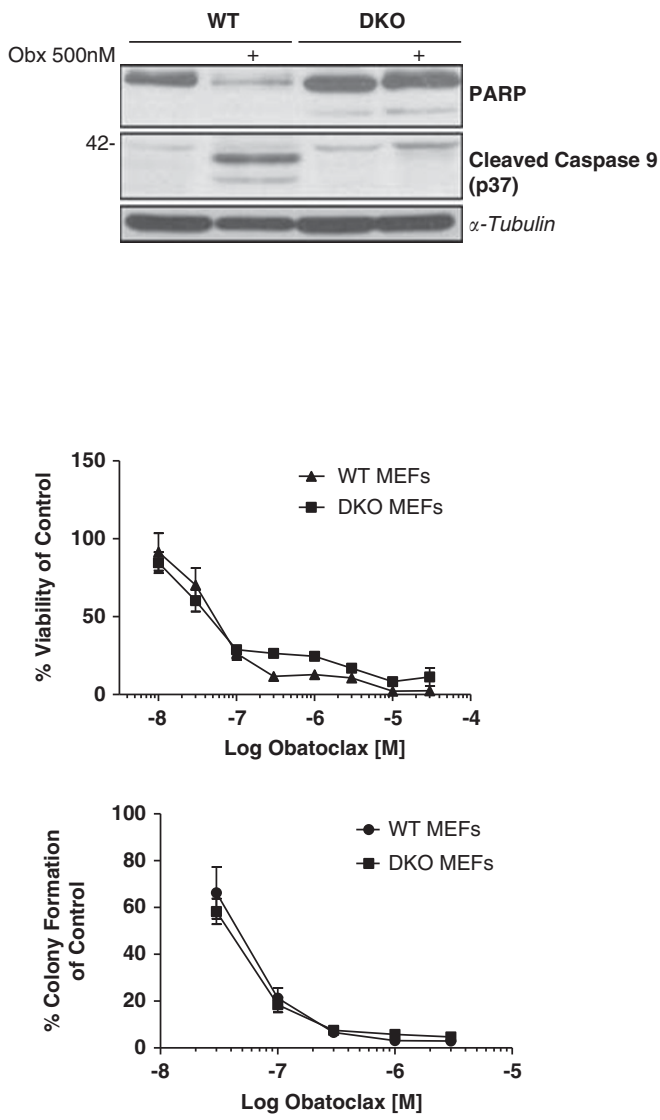

- WT MEF - contro

- WT MEF - 500nM obx

- DKO MEF - contro

Figure 2 Obatoclax-induced apoptosis is dependent upon BAX/BAK, yet loss of BAX/BAK fails to rescue cells. (a) Loss of BAX and BAK inhibits obatoclax-induced apoptosis in H460 NSCLC cells. Apoptosis is blocked in NSCLC cells deficient for BAX/BAK. H460 NSCLC cells were stably transfected with shRNAs simultaneously targeting BAX and BAK $\left(\mathrm{H} 460^{\text {shBAX/BAK }}\right)$, or with two non-targeting shRNAs as control cells $\left(\mathrm{H} 460^{\text {shNT/NT}}\right)$. Two clones of shBAX/BAK cells were taken forward to examine $\left(\mathrm{H} 460^{\text {shBAXBAK } 4 \mathrm{C}}\right.$ and $\mathrm{H} 460^{\text {shBAX/ }}$ BAK 1B). H460 $0^{\text {shNTNT }}$ and H460 ${ }^{\text {shBAXBBAK } 4 C}$ cells were treated with $1 \mu \mathrm{M}$ obatoclax for $48 \mathrm{~h}$. Cell lysates were probed for PARP, caspase 9 and caspase 3 cleavage by SDS-PAGE. GAPDH was used as a loading control. The level of BAX and BAK knockdown in both clones was assessed by SDS-PAGE (samples run in duplicate). $\beta$-Actin served as a loading control. (b) Obatoclax-induced apoptosis is blocked in embryonic fibroblasts derived from mice deficient for BAX and BAK. Wild type (WT) and BAX/BAK double-knockout (DKO) mouse embryonic fibroblasts (MEFs) were treated with $500 \mathrm{nM}$ obatoclax for $48 \mathrm{~h}$ and the level of PARP and caspase 9 cleavage determined by SDS-PAGE. $\alpha$-Tubulin was used as a loading control. (c) Loss of BAX/BAK fails to rescue cells following obatoclax. The effect of obatoclax on the viability of H460 ${ }^{\text {shBAXBBAK }}$ and BAX/BAK DKO MEFs was assessed by ViaLight viability assay (Lonza Group Ltd.). EC 50 values for each cell line were; H460 ${ }^{\text {shNTNT }} 690 \mathrm{nM} ; \mathrm{H}_{46} 0^{\text {shBAXBAK }}{ }^{1 \mathrm{~B}} 580 \mathrm{nM} ; \mathrm{H} 460^{\text {shBAXBAK } 4 \mathrm{C}} 460 \mathrm{nM}$; WT MEFs $54 \mathrm{nM}$; DKO MEFs $62 \mathrm{nM}$. Each data point represents mean \pm S.D. (d) Cells were plated at single-cell densities and treated with indicated doses of obatoclax for $24 \mathrm{~h}$. Medium was replaced and cells were allowed to form colonies. Each data point represents mean \pm S.E. (e) Loss of BAX/BAK fails to rescue cells over the long term. Cells were seeded in 6 -well plates and drugged at indicted doses. Cells were then monitored using the INCUCYTE live cell imaging system (Essen BioScience). Cell confluency was determined using calculations derived from phase-contrast images. This data was condensed using algorithms into quantified metrics to obtain kinetic proliferation curves

effective in reducing viability in $\mathrm{H} 460^{\text {shBAX/BAK }}$ versus $\mathrm{H} 460^{\text {shNT/NT }}$ control cells and in BAX/BAK DKO MEFs versus WT controls at both $48 \mathrm{~h}$ (Figure $2 \mathrm{c}$ ) and $72 \mathrm{~h}$ (data not shown). $\mathrm{H} 460^{\text {shBAX/BAK }}$ cells exhibited a dose-dependent loss of clonogenicity not significantly different from $\mathrm{H} 460^{\text {shNT/ }}$ NT cells (Figure 2d). Similarly, no difference in the loss of clonogenicity was observed following Obatoclax treatment in BAX/BAK DKO versus WT MEFs (Figure 2d). Also, when the 
growth kinetics of DKO MEFs was assessed over 5 days following obatoclax treatment, there was no significant difference relative to their WT controls (Figure 2e).

Obatoclax induces processing of light chain-3 (LC3) and dramatic ultrastructural changes. Despite the marked reduction in cell viability induced by obatoclax, there was no measurable loss of plasma membrane integrity following $72 \mathrm{~h}$ (Figure 3a) or $96 \mathrm{~h}$ (data not shown) exposure, as determined by adenylate kinase release into surrounding culture media relative to untreated controls. This was in contrast to tumor necrosis receptor-related apoptosis-inducing ligand

a
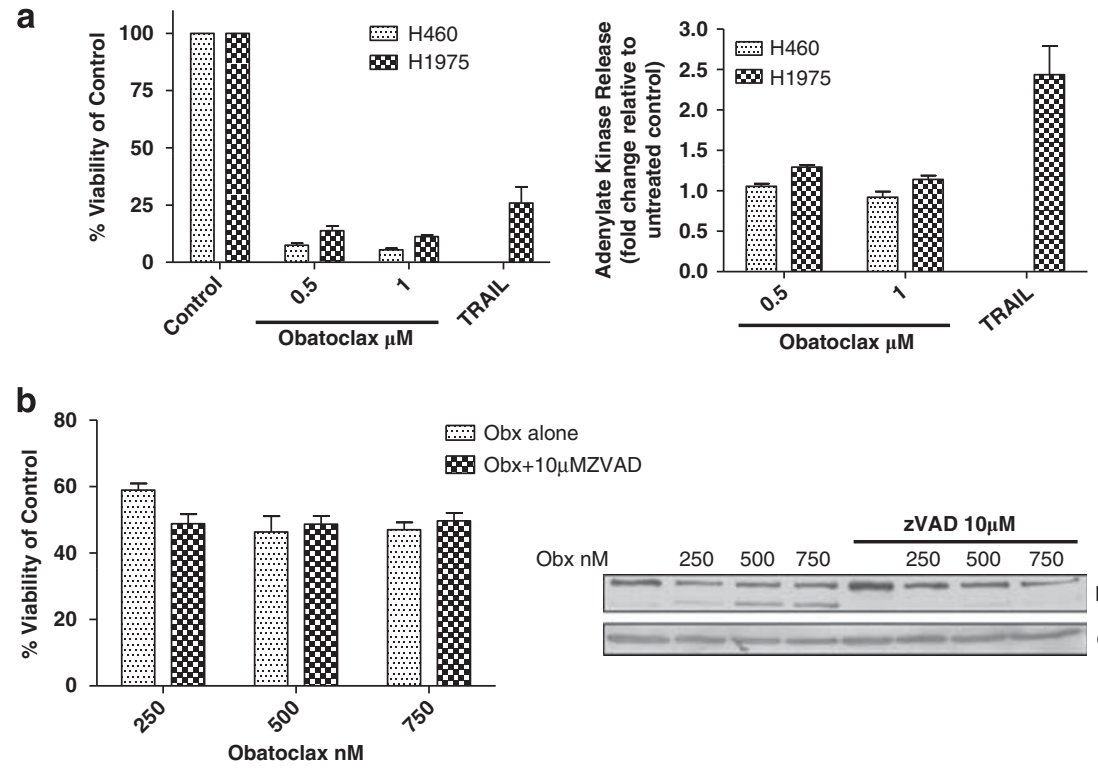

.7. Obx alone

C
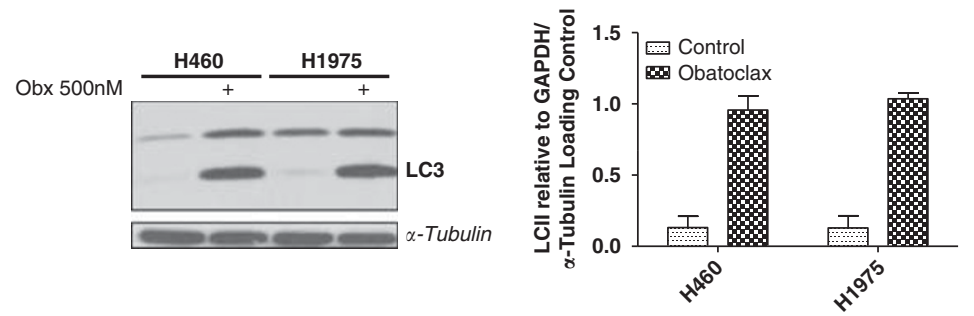

d

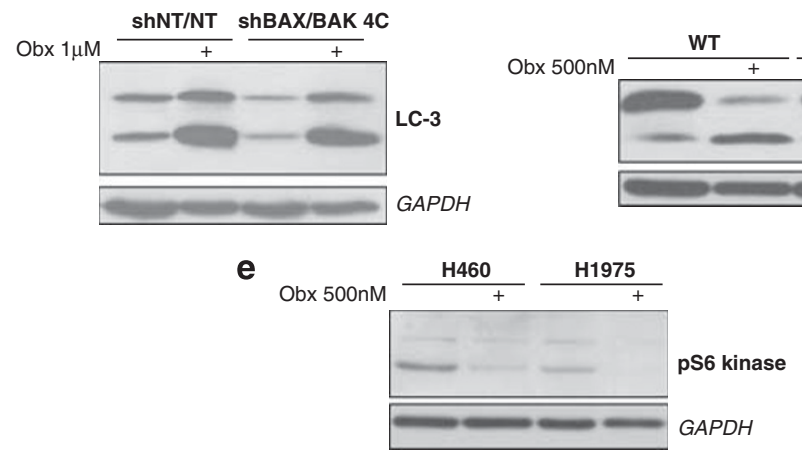

Figure 3 Cell fate following obatoclax is determined by additional mechanisms other than apoptosis. (a) Obatoclax fails to induce loss in plasma membrane integrity. (left) H460 and H1975 NSCLC cells were treated at indicated doses of obatoclax for $72 \mathrm{~h}$. $\mathrm{H} 1975$ cells were also treated with $20 \mathrm{ng} / \mathrm{ml}$ TNF-receptor-related apoptosis-inducing ligand (TRAIL). Viability of cells was assessed by ViaLight viability assay (Lonza Group Ltd.). Data are expressed as mean \pm S.D. (right) H460 and H1975 cells were treated as for ViaLight, however, this time toxicity of cells was assessed by ToxiLight cytotoxicity assay (Lonza Group Ltd.). Data are expressed as mean \pm S.D. (b) Inhibition of obatoclax-induced apoptosis by ZVAD.fmk fails to rescue cells. (left) H1975 cells were treated with $10 \mu \mathrm{M}$ pan caspase inhibitor ZVAD.fmk for 30 min before treatment with indicated doses of obatoclax for $48 \mathrm{~h}$. Viability of cells was assessed by ViaLight viability assay. Data are expressed as mean \pm S.D. (right). The effect of ZVAD on obatoclaxinduced PARP cleavage was assessed by SDS-PAGE. GAPDH was used as a loading control. (c) Obatoclax induces significant processing of LC3. (left) H460 and H1975 cells were treated with $500 \mathrm{nM}$ obatoclax for $48 \mathrm{~h}$ and the level of LC3 processing assessed by SDS-PAGE. (right) Quantification of the level of LC3 processing following obatoclax was achieved by densitometry analysis using ImageJ. Data are expressed as mean \pm S.D. (d) Obatoclax-induced LC3 processing is independent of BAX and BAK. (left) $\mathrm{H} 460^{\text {shBAX/BAK } 4 \mathrm{C}}$ cells were treated with $1 \mu \mathrm{M}$ obatoclax for $48 \mathrm{~h}$ and the level of LC3 processing assessed by SDS-PAGE. GAPDH was used as a loading control. (right) Wild type and BAX/BAK DKO MEFs were treated with $500 \mathrm{nM}$ obatoclax for $48 \mathrm{~h}$ and the level of LC3 processing assessed by SDS-PAGE. $\alpha$-Tubulin served as a loading control. (e) Obatoclax induces de-phosphorylation of S6 kinase. H460 and H1975 cells were treated with $500 \mathrm{nM}$ obatoclax for $48 \mathrm{~h}$ and the level of S6 kinase phosphorylation determined by SDS-PAGE and immunoblotting with a phospho-S6 kinase antibody that detects phosphorylation of thr389. GAPDH was used as a loading control 
(TRAIL). Furthermore, the pan-caspase inhibitor ZVAD.fmk failed to prevent loss of viability following obatoclax treatment, although it blocked obatoclax-induced PARP cleavage (Figure $3 b$ ). Together these findings suggested that cell fate following treatment with obatoclax is determined by additional mechanisms other than apoptosis.

Autophagy is a catabolic process involving dynamic re-arrangement of membranes and formation of autophagosomes and autolysosomes. Light chain 3 (LC3, mammalian ortholog of yeast Atg8) is widely used as a reporter of autophagosome formation. During autophagy cytoplasmic LC3-I is processed to the autophagosomal membrane-bound LC3-II form. In two NSCLC cell lines (H460 and H1975); we observed significant processing of LC3-I to LC3-II relative to untreated controls (Figure $3 \mathrm{c}$ ). LC3 processing was independent of $B A X$ and BAK as evidenced from $\mathrm{H} 460^{\text {shBAX/BAK }}$ cells and BAX/BAKDKO MEFs in which processing occurred to an equivalent extent as that observed in their respective controls
(Figure 3d). Also, p70-S6 kinase was de-phosphorylated following obatoclax treatment in $\mathrm{H} 460$ and $\mathrm{H} 1975$ cells (Figure 3e).

Autophagy is associated with characteristic autophagolysosome formation best observed using electron microscopy. Compared with untreated controls (Figure 4a), obatoclax induced a profound cytoplasmic vacuolation in H1975 cells visible by transmission electron microscopy (Figure 4b). These vacuoles were mainly devoid of obvious content, although a few exhibited some electron-dense material within their lumina. At higher magnification, the peripheral cytoplasm revealed vesicles containing phagocytosed organelles, free ribosomes and endoplasmic reticulum (Figure 4c). Mitochondria were found to form part of the autophagocytosed pay-load within vesicles (Figures $4 \mathrm{~d}$ and e). Profound cytoplasmic vacuolation similar to that seen in H1975 NSCLC cells along with significant LC3 processing was also observed in small-cell lung cancer cell lines following obatoclax treatment (data not shown).
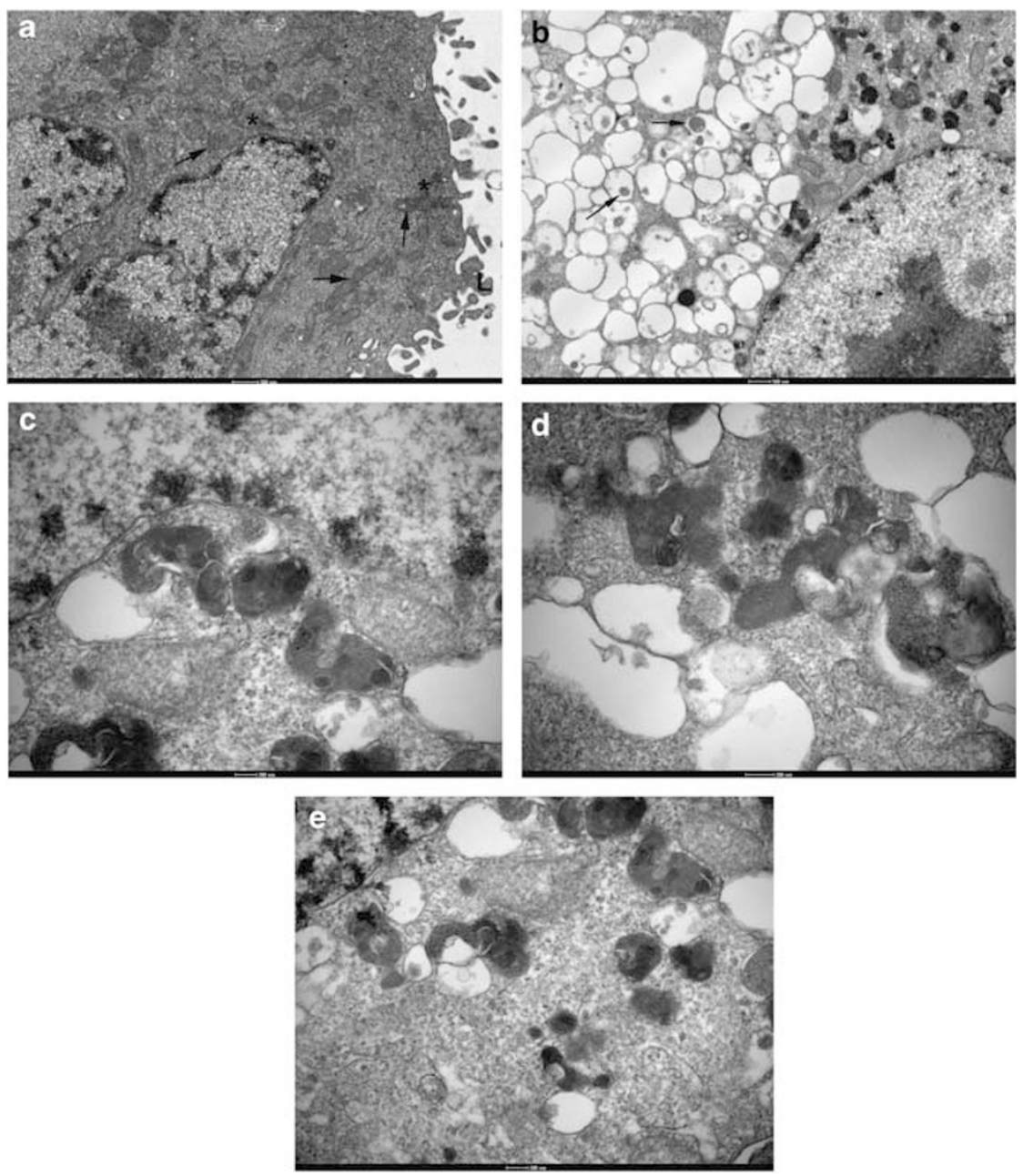

Figure 4 Obatoclax induces dramatic ultrastructural vacuolation in H1975 NSCLC cells. (a) H1975-untreated control cells. Untreated cells were processed by the standard protocol adopted for all other samples. The cytoplasm appears normal and is typified by the presence of numerous mitochondria (arrows), cisternae of endoplasmic reticulum $\left.{ }^{*}\right)$ and an extensive array of superficial lamellae (L). The nucleus exhibits scattered arrays of condensed heterochromatin, frequent nuclear pores and a prominent nucleolus. (b) Following $48 \mathrm{~h}$ treatment with $500 \mathrm{nM}$, obatoclax seems to induce a profound vesiculation of the cytoplasm. Many of these membrane vesicles are devoid of obvious content, although a few exhibit some electron dense material within their lumina (arrows). At this stage the nuclei do not appear to have suffered any change. (c) Higher magnification of peripheral cytoplasm reveals that vesicle content is of mixed origin comprising phagocytosed organelles, free ribosomes and endoplasmic reticulum. (d and e) Mitochondria form part of the autophagocytosed pay-load within vesicles, although none have been found to undergo any significant change to their inner membranes 
Obatoclax-induced LC3 processing is independent of beclin-1. Beclin-1 (human ortholog of yeast Atg-6) is a key apical regulator of autophagy. It is constitutively bound by pro-survival BCL-2 family proteins $\mathrm{BCL}-\mathrm{xl}, \mathrm{BCL}-2$ and $\mathrm{MCL}-1$. We therefore examined the role of beclin-1 with respect to LC3 processing following obatoclax treatment. H460 NSCLC cells stably expressing short hairpin RNAs targeting BECN1 $\left(\mathrm{H} 460^{\mathrm{BECN}}\right)$ were established and three clones selected ( $\mathrm{H} 460^{\text {shBECN } 3 E}, \mathrm{H} 460^{\text {shBECN } 3 \mathrm{~F}}$ and $\mathrm{H} 460^{\text {shBECN } 4 \mathrm{E}}$ ) displaying between 60-90\% knockdown (Figure 5a). Stable knockdown of beclin-1 did not alter the sensitivity of $\mathrm{H} 460$ cells to obatoclax as assessed by ViaLight viability assay (data not shown). Consistent with loss of beclin-1, each clone exhibited a reduction in hVps34-specific activity, indicating a functional defect in hVps34 signaling, both basally and following acute nutrient deprivation (Figure 5b). Loss of beclin-1 expression did not significantly alter obatoclaxinduced LC3 processing in any of the clones (Figure 5c), and was confirmed using transient siRNA silencing (Figure 5d). Consistent with these findings, neither 3-methyladenine nor wortmannin were capable of inhibiting LC3 processing following obatoclax treatment (data not shown). Furthermore, obatoclax treatment in H1975 and H460 NSCLC cells caused a significant reduction in beclin-1 expression (Figure 5e).

Obatoclax-induced LC3 processing requires Atg7. To establish whether autophagy machinery was required at all for LC3 processing following obatoclax treatment, we next assessed whether there was a requirement for Atg7 using
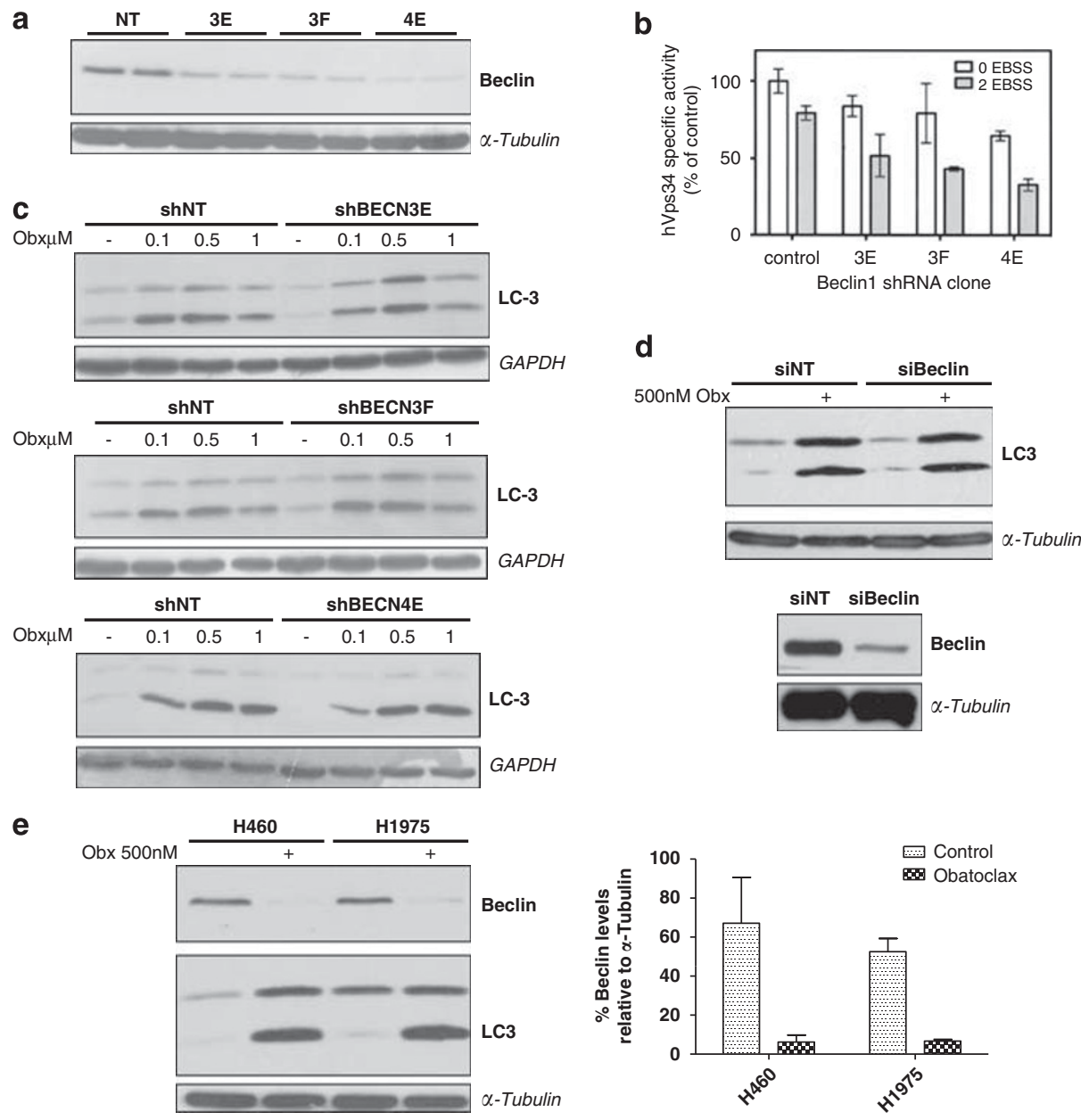

Figure 5 Obatoclax-induced autophagy is independent of beclin-1. (a) H460 NSCLC cells were stably transfected with shRNA targeting beclin-1 (H460 ${ }^{\text {shBECN }}$ ). Three stable clones were selected (3E, 3F, and 4E) displaying significant knockdown in the level of beclin-1 as assessed by SDS-PAGE (samples run in duplicate), relative to control cells stably transfected with a non-targeting shRNA $\left({\mathrm{H} 460^{\text {shNT }}}\right)$. $\alpha$-Tubublin was used a loading control. (b) hVps34 activity is reduced in $\mathrm{H} 460^{\text {shBECN }}$ cells. hVps34-specific lipid kinase activity was determined in each $\mathrm{H} 460^{\text {shBECN }}$ clone. Cells were cultured to $80-90 \%$ confluency then washed three times in PBS before depriving them of amino acids for 0 and $2 \mathrm{~h}$ in EBSS. hVps34 activity was expressed as specific activity after normalizing to the amount of immunoprecipitated hVps 34 detected by immunoblotting. Data are expressed as mean \pm S.D. (c) Stable knockdown of beclin- 1 fails to inhibit obatoclax-induced LC3 processing. $H 460^{\text {shBECN }}$ and $H 460^{\text {shNT }}$ cells were treated with indicated doses of obatoclax for $48 \mathrm{~h}$ and the level of $\mathrm{LC} 3$ processing in each clone relative to $\mathrm{H} 460^{\mathrm{shNT}}$ cells was determined by SDS-PAGE. GAPDH was used as a loading control. (d) Transient knockdown of beclin-1 fails to inhibit obatoclax-induced LC3 processing. H460 NSCLC cells were transfected with $100 \mathrm{nM}$ of siRNA targeting beclin-1 or control non-targeting (NT) siRNA for $48 \mathrm{~h}$. NT- and beclin-1-transfected cells were then treated with $500 \mathrm{nM}$ obatoclax for $48 \mathrm{~h}$. The level of LC3 processing and PARP cleavage was determined by SDS-PAGE. The level of beclin- 1 knockdown was also determined by SDS-PAGE. $\alpha$-Tubulin was used as a loading control. (e) Levels of beclin1 decrease significantly following obatoclax treatment. $\mathrm{H} 460$ and $\mathrm{H} 1975$ cells were treated with $500 \mathrm{nM}$ obatoclax for $48 \mathrm{~h}$ and the levels of beclin-1 determined by SDSPAGE. $\alpha$-Tubulin was used as a loading control. The level of beclin-1 decrease was quantified by densitometry analysis using ImageJ. Data represent mean \pm S.D. 
RNA interference. Atg7 plays a pivotal role in the formation of autophagosomes. When expression of Atg7 was silenced using siRNA, LC3 processing was reduced in both $\mathrm{H} 460$ and H1975 cells. siRNA knockdown of Atg5 also attenuated LC3 processing (Figure 6a). To definitively confirm a requirement for Atg7, we examined the levels of LC3 processing and cytoplasmic vacuolation in $A \operatorname{tg} 7^{-1-}$ MEFs; LC3 processing (Figure 6b) and cytoplasmic vacuolation (data not shown) were completely abolished following obatoclax treatment. However, induction of apoptosis assessed by PARP cleavage was not affected by loss of Atg7 (Figures 6a and b), however, siRNA knockdown of Atg5 in $\mathrm{H} 460$ cells altered the pattern of PARP cleavage; there was a reduction in fulllength PARP but no cleaved $89 \mathrm{kDa}$ product detectable (Figure 6a).

\section{Autophagy is not essential for obatoclax-induced toxicity. To assess whether autophagy was a requirement for obatoclax-induced toxicity, we examined the effect of Atg7 knockout on viability and long-term clonogenicity of $A \operatorname{tg} 7^{-1-}$ MEFs treated with obatoclax. Obatoclax reduced the viability of $A \operatorname{tg} 7^{-1-}$ MEFs and WT MEFs equally, with no significant difference in their relative $\mathrm{EC}_{50}$ (Figure $6 \mathrm{c}$ ). Loss of clonogenicity was observed in $\mathrm{Atg} 7^{-1-} \mathrm{MEFs}$ with no difference relative to their WT controls (Figure 6d), while the long-term growth kinetics of $\mathrm{Atg} 7^{-/-}$MEFs was not significantly different from their WT controls following obatoclax treatment (Figure 6e). siRNA silencing of Atg7 in Bax/Bak DKO MEFs did significantly rescue cells treated with obatoclax, however, this rescue was not total (Figure 6f). siRNA knockdown of Atg7 in BAX/BAK DKO MEFs completely abolished LC3 processing (data not shown).}

Obatoclax resistance is associated with a block in apoptosis and a reduction in autophagy. To establish whether cells that are resistant to obatoclax suppress autophagy as well as apoptosis, we screened a panel of cell lines for obatoclax resistance and identified $\mathrm{H} 727$ NSCLC cells with log-fold resistance to obatoclax compared with H1975 and H460 NSCLC cells (Figure 7a). $\mathrm{H} 727$ cells also displayed significant differences in their clonogenic survival in response to obatoclax (Figure 7b) and failed to undergo caspase 3, caspase 9 or PARP cleavage (Figure 7c). We wanted to examine the kinetics of apoptosis and autophagy induction to further try and delineate their relationship. In both $\mathrm{H} 1975$ and $\mathrm{H} 727$ NSCLC cells, LC3 processing was observed as early as $6 \mathrm{~h}$ following obatoclax treatment, which increased and was sustained through to $48 \mathrm{~h}$ in both cell lines. PARP cleavage however, was only observed in sensitive $\mathrm{H} 1975$ cells, and only significantly at 48h, whereas no PARP cleavage was observed in $\mathrm{H} 727$ cells (Figure $7 \mathrm{~d}$ ), even up to 72 and $96 \mathrm{~h}$ post drug exposure (data not shown). When examined by TEM, H727 cells also exhibited cytoplasmic vacuolation post obatoclax exposure (data not shown). Similar to $\mathrm{H} 1975$ and $\mathrm{H} 460$ cells, H727 NSCLC cells also underwent de-phosphorylation of S6 kinase following obatoclax treatment (data not shown).

To further determine the role of apoptosis and autophagy in mediating resistance to obatoclax, we selected $\mathrm{H} 460$ NSCLC cells for obatoclax resistance using ENU to induce mutagenesis. H460 obatoclax-resistant cells (H460-ENU) displayed a significantly higher $\mathrm{EC}_{50}$ for viability at $48 \mathrm{~h}$, and greater clonogenic survival relative to parental H460s (H460par) (Figure 8a). In common with H727 cells, PARP and caspase 9 cleavage were both blocked in H460-ENU cells, and this was associated with absence of obatoclaxinduced SMAC and cytochrome $c$ release (Figures $8 b$ and $c$ ). Processing of LC3 following obatoclax treatment was also observed in H460-ENU cells; however, this was to a lesser extent than in H460par cells (Figure 8b). Profiling of BCL-2 family expression was conducted to establish if acquired resistance to obatoclax was associated with alterations in BCL-2 family expression, however, no significant differences were observed at either the whole-cell or mitochondrial level (data not shown).

\section{Discussion}

Obatoclax is one of several pro-survival BCL-2 family protein inhibitors to have emerged in recent years and is currently in clinical development in both solid tumors and hematopoietic malignancies. In this study, we investigated the pharmacodynamics of obatoclax. We found that in NSCLC cells, obatoclax induced both on-target dissociation of MCL-1-BAK complexes and initiation of apoptosis associated with mitochondrial BAK conformation change and release of cytochrome $c$ and SMAC. A requirement of BAX and BAK for obatoclax-induced apoptosis has been shown in other models previously. Nguyen et al. (2007) found that in baby kidney epithelial cells from mice deficient for BAX and BAK obatoclax failed to induce apoptosis, ${ }^{18}$ whereas Mott et al. (2008) showed that DKO MEFs were resistant to obatoclax-induced cell death as assessed by clonogenic assay. ${ }^{20}$ However, Vogler et al. (2009) investigating cell death induced by obatoclax (as well as other pro-survival BCL-2 family inhibitors) suggested that obatoclax caused cell killing completely independently of BAX and BAK, and did not activate the intrinsic apoptosis pathway, but rather acted as a mitochondrial poison that induced features that could be mistaken as apoptosis. ${ }^{24}$ However, we have shown here that apoptosis as assessed by caspase and PARP cleavage (specific markers of apoptosis) induced by obatoclax is dependent on BAX and BAK. Furthermore, the conclusion reached by Vogler et al. ${ }^{24}$ that obatoclax acts as a mitochondrial poison was reached from the results of experiments using $10 \mu \mathrm{M}$ doses of obatoclax, a dose that is up to two log-folds higher than what we have used in results presented here, and significantly higher than clinically relevant doses. Doses used differ according to trial schedules; however, the approximate peak plasma concentration is $100 \mathrm{ng} / \mathrm{ml}(\sim 250 \mathrm{mM})$.

We have shown that despite the evidence that obatoclax induces BAX/BAK-dependent apoptosis, this is not sufficient to account for toxicity and loss of clonogenic survival, as evidenced by sensitivity of BAX and BAK DKO MEFs, and cell lines stably expressing shRNAs for BAX and BAK. Obatoclax mediates loss of clonogenic survival in association with a marked reduction in growth kinetics and reduction in cellular ATP level without loss of plasma membrane integrity. This suggested that obatoclax could be inducing loss of viability by a mechanism distinct from apoptosis and prompted 

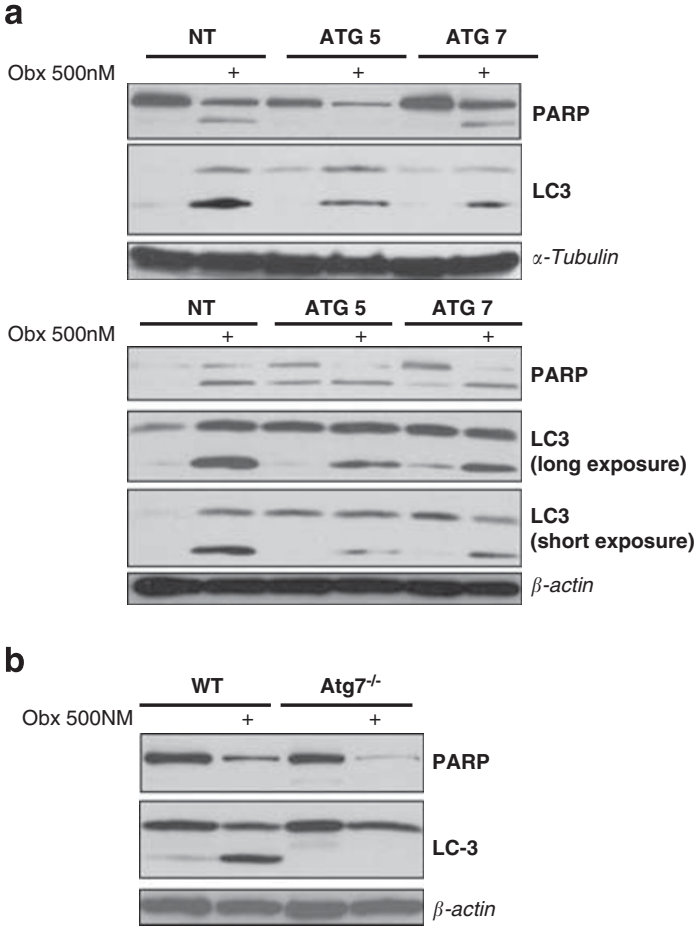
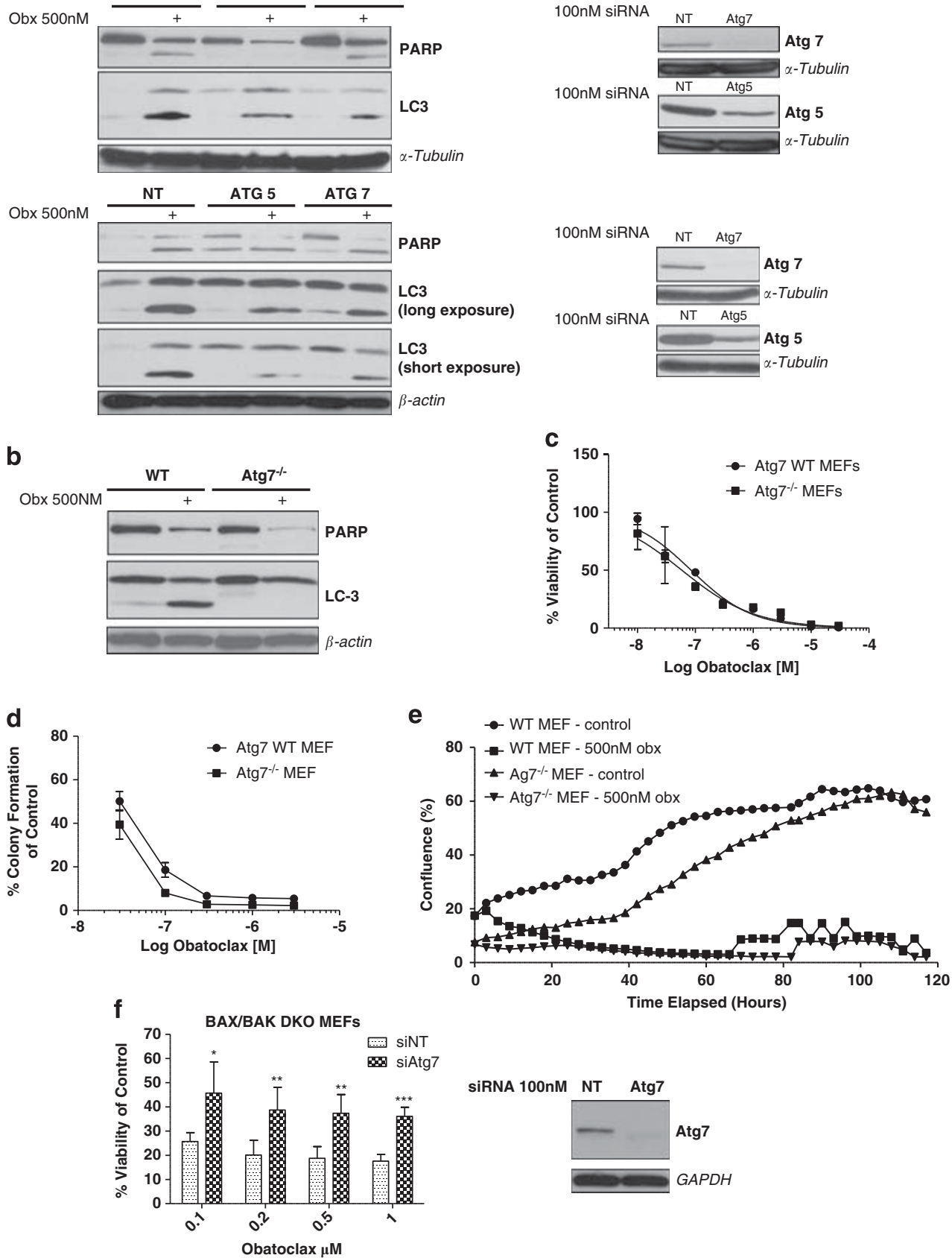

siRNA 100nM NT Atg7

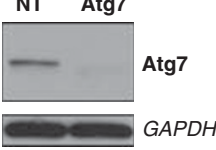

Figure 6 Obatoclax-induced LC3 processing requires Atg7 and Atg5. (a) siRNA knockdown of Atg5/7 reduces obatoclax-induced LC3 processing. H460 (top) and H1975 (bottom) cells were transfected with $100 \mathrm{nM}$ of Atg7 or Atg5 siRNA, or control non-targeting siRNA (NT) for $48 \mathrm{~h}$, and then treated with $500 \mathrm{nM}$ obatoclax for a further $48 \mathrm{~h}$. The level of LC3 processing and PARP cleavage in Atg5/7-transfected cells relative to NT-transfected cells was then determined by SDS-PAGE. $\alpha$-Tubulin and $\beta$-actin were used as loading controls. (b) Obatoclax-induced LC3 processing is lost in mouse embryonic fibroblasts derived from mice deficient for Atg7. Wild-type and Atg7 ${ }^{-1-}$ MEFs were treated with $500 \mathrm{nM}$ obatoclax for $48 \mathrm{~h}$ and the level of LC3 processing and PARP cleavage was determined by SDS-PAGE. $\beta$-Actin was used as a loading control. (c) Autophagy is not essential for obatoclax-induced toxicity. The effect on the viability of Atg $7^{-1-}$ MEFs and their wild-type controls following obatoclax treatment for $48 \mathrm{~h}$. $\mathrm{EC}_{50}$ values for each cell line were; Atg7 WT $84 \mathrm{nM}$; Atg $7^{-1-} 58 \mathrm{nM}$. Data are presented as mean \pm S.D. (d) Loss of Atg7 fails to rescue cells. Atg7 wild-type and Atg $7^{-1-}$ cells were plated in 24-well plates at single-cell densities and treated with indicated doses of obatoclax for $24 \mathrm{~h}$. Media was replaced after $24 \mathrm{~h}$ and cells allowed to form colonies over 7-10 days to assess the effect of obatoclax on clonogenic growth. Data are presented mean \pm S.E. (e) Loss of Atg7 fails to rescue cells over the long term. Cells were seeded in 6-well plates and drugged at indicted doses. Cells were then monitored using the INCUCYTE live cell imaging system (Essen BioScience). Cell confluency was determined using calculations derived from phase-contrast images. This data was condensed using algorithms into quantified metrics to obtain kinetic proliferation curves. (f) siRNA knockdown of Atg7 rescues BAX/BAK DKO MEFs. DKO MEFs were transfected with $100 \mathrm{nM}$ of Atg7 siRNA or control non-targeting siRNA (NT) for $48 \mathrm{~h}$. Cells were then treated with indicated doses of obatoclax for a further $48 \mathrm{~h}$ and the effect on viability determined by ViaLight assay. Data are presented as mean \pm S.D. The level of knockdown was determined by SDS-PAGE. GAPDH was used as a loading control 
a
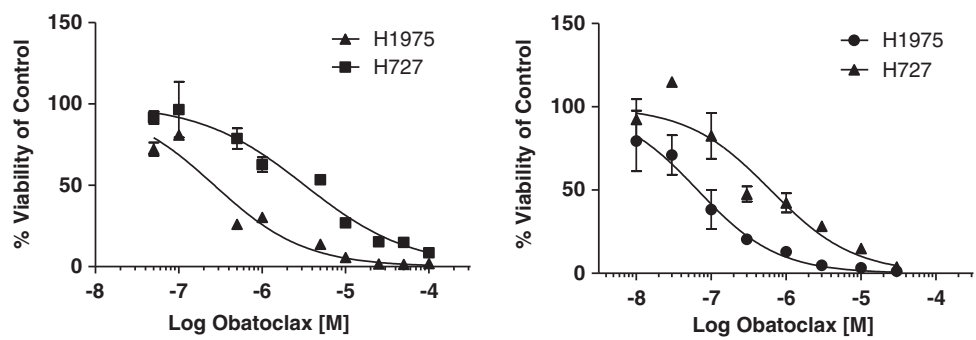

C
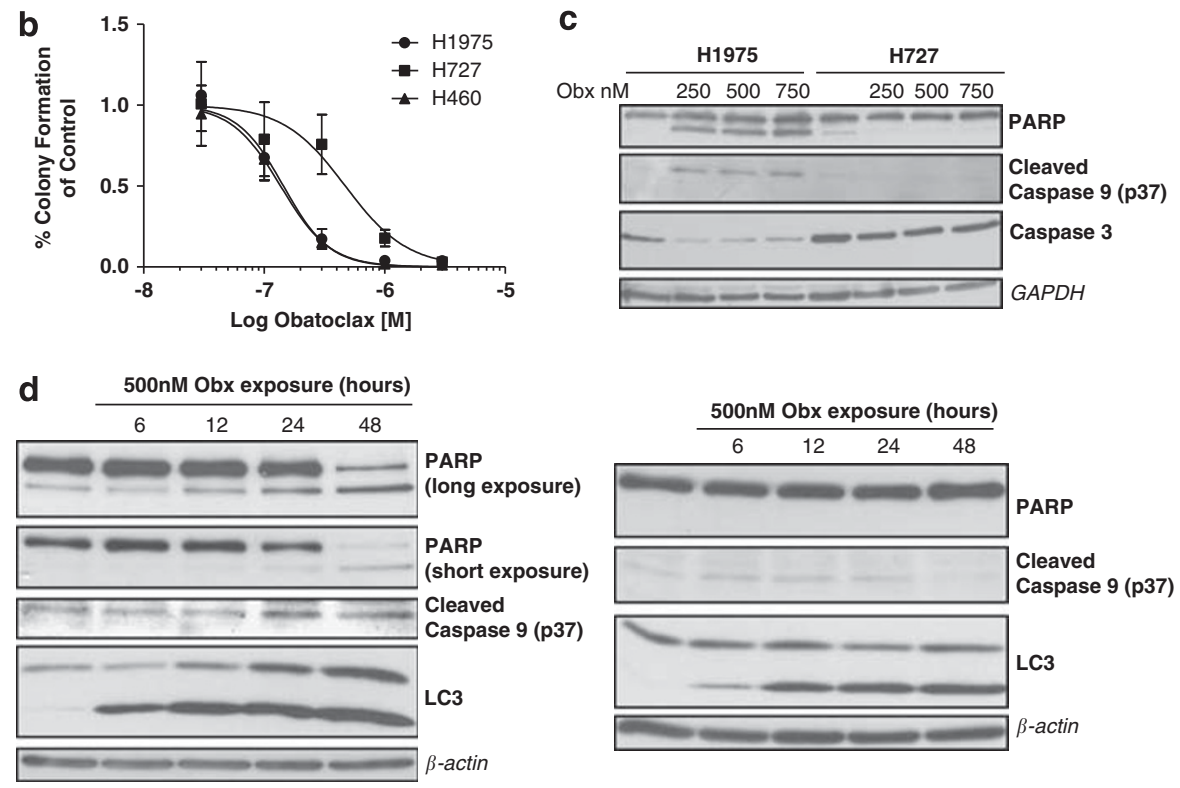

Figure 7 H727 NSCLC cells are resistant to obatoclax-induced apoptosis yet still undergo autophagy. (a) H727 NSCLC cells are resistant to obatoclax. H727 and H1975 NSCLC cells were treated with obatoclax at the indicated doses for 48 (left) or $72 \mathrm{~h}$ (right), and the viability of cells determined by ViaLight assay. The EC ${ }_{50}$ values of cells at $48 \mathrm{~h}$ were; H1975 $267 \mathrm{nM}$; H727 $3.2 \mu \mathrm{M}$. The $\mathrm{EC}_{50}$ values of cells at $72 \mathrm{~h}$ were; H1975 $66 \mathrm{nM}$; H727 $621 \mathrm{nM}$. Data are expressed as mean \pm S.D. (b) H727 cells display increased clonogenic survival. H727, H1975 and H460 NSCLC cells were seeded in 24-well plates at single cell densities, and treated with indicated doses of obatoclax for $24 \mathrm{~h}$. Media was replaced after $24 \mathrm{~h}$ and cells allowed to form colonies over 7-10 days to assess the effect of obatoclax on clonogenic growth. Data are presented as mean \pm S.E. (c) H727 NSCLC cells are resistant to obatoclax-induced apoptosis. H1975 and H727 NSCLC cells were treated with indicated doses of obatoclax for $48 \mathrm{~h}$ and the level of PARP, caspase 9 and caspase 3 cleavage determined by SDS-PAGE. GAPDH was used as a loading control. (d) Cells resistant to obatoclax-induced apoptosis still undergo obatoclax-induced autophagy. H1975 (left) and H727 (right) cells were treated with $500 \mathrm{nM}$ obatoclax for the indicated time periods and the level of PARP, caspase 9 cleavage and LC3 processing was determined by SDS-PAGE. $\beta$-Actin was used as a loading control

us to examine the role of the autophagy machinery. Obatoclax has been shown to induce autophagy in several reports. ${ }^{24-28}$ In contrast to all earlier studies, this is the first report to show a beclin-1-independent mechanism of obatoclax-induced autophagy.

Beclin-1 is an initiator of autophagy that contains a $\mathrm{BH} 3$ domain and is restrained by pro-survival $B C L-2$ family proteins BCL-2, BCL-xl, BCL-w and MCL-1. ${ }^{29-31}$ However, only endoplasmic reticulum-targeted $\mathrm{BCL}-2 / \mathrm{xl}$ can inhibit autophagy induced by beclin- $1 .{ }^{30}$ Inhibition of pro-survival BCL-2 family proteins releases beclin- 1 , which binds and activates Vps34 lipid kinase and induces formation of the phagophore. ${ }^{32}$ Beclin-1 has also been shown to be a haploinsufficient tumor suppressor, ${ }^{33,34}$ and it has been suggested that displacement of beclin- 1 from its BCL-2 binding partners may be a means to induce a toxic form of autophagy in cancer cells, ${ }^{35}$ known as type II programmed cell death. Furthermore, it has been shown that in the absence of BAX and BAK, induction of autophagy was used as a default cell death mechanism. ${ }^{36}$ Accordingly, we explored the activation of autophagy by obatoclax, the requirement for components of the autophagy machinery and the implications for cell fate.

Using stable and transient knockdown of beclin-1, we showed that the biochemical hallmark of autophagy, LC3 processing, occurs irrespective of beclin-1 expression, but is entirely dependent upon the expression of Atg7. Induction of apoptosis as assessed by PARP cleavage was unaffected by loss of Atg7 (or Atg5), however, loss of Atg5 in $\mathrm{H} 460$ cells did alter the pattern of PARP cleavage (see Figure 6a); there was a reduction in full-length PARP but no appearance of a cleaved $89 \mathrm{kDa}$ fragment indicative of apoptosis. During necrosis PARP can be cleaved to a $50 \mathrm{kDa}$ fragment by lysosomal proteases ${ }^{37}$ however, this is unlikely to be the case in regards to obatoclax. As shown in Figure 3a, obatoclax failed to induce a loss of plasma membrane integrity, which would not be the case if necrosis was being induced. The mechanism underlying Atg7-dependent, beclin-1-independent autophagy by obatoclax is unclear. Another pro-survival 

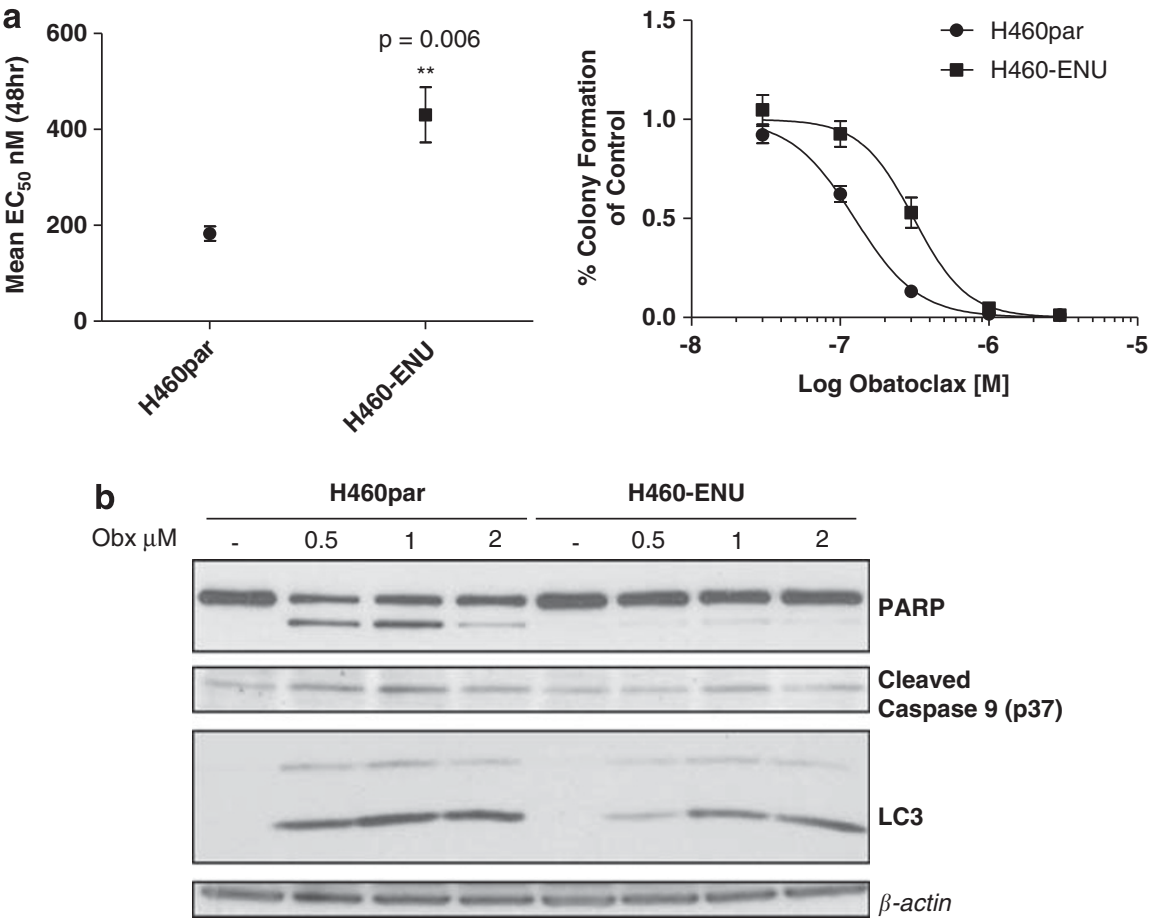

C

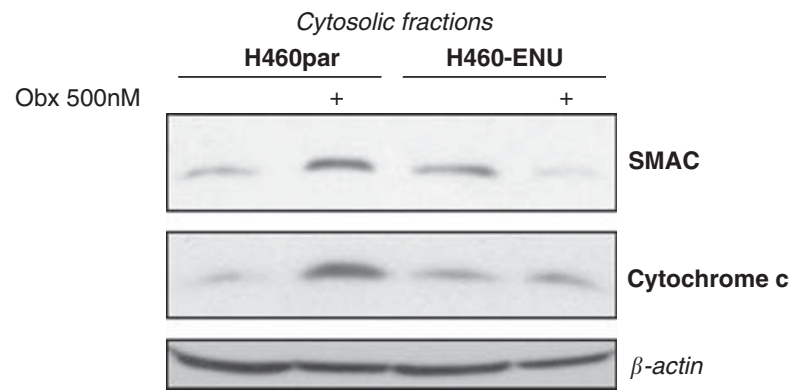

Figure 8 NSCLC cells selected for resistance to obatoclax display a block in apoptosis. (a) H460 NSCLC cells were selected for resistance to obatoclax (H460-ENU) using ENU mutagenesis as described in the Materials and Methods. (left) $\mathrm{H} 460-\mathrm{ENU}$ cells displayed a significant increase in their $\mathrm{EC}_{50}$ value as determined by ViaLight assay. (right) H460 parental (H460par) cells and H460-ENU cells were seeded as previously described for clonogenic assay and treated with indicated doses of obatoclax to assess the effect of obatoclax on clonogenic growth. (b) H460-ENU cells are resistant to obatoclax-induced apoptosis and display reduced LC3 processing. H460par and H460-ENU cells were treated with indicated doses of obatoclax for $48 \mathrm{~h}$ and the level of PARP, caspase 9 cleavage and LC3 processing was determined by SDS-PAGE. $\beta$-Actin was used as a loading control. (c) H460-ENU cells displayed a block in SMAC and cytochrome $c$ release. $\mathrm{H} 460$ and H460-ENU cells were treated with $500 \mathrm{nM}$ obatoclax for $48 \mathrm{~h}$. The cytosolic fraction of cells was isolated as described in Materials and methods and the levels of SMAC and cytochrome $c$ determined by SDS-PAGE. $\beta$-Actin was used as a loading control

BCL-2 antagonist, gossypol, has very recently been shown to induce both beclin-1-dependent and -independent autophagy; ${ }^{38}$ in MCF-7 cells, gossypol-induced autophagy was beclin-1-dependent, whereas in HeLa cells it was beclin1-independent. Regardless of the cell line, gossypol-induced autophagy was found to be cytoprotective. In neuroblastoma cells, the neurotoxin 1-methyl-4-phenylpyridinium (MPP ${ }^{+}$), a mitochondrial complex 1 inhibitor, was found to induce mitochondrial injury and beclin-1-independent Atg5/7-dependent mitophagy. ${ }^{39}$ Whether obatoclax is acting in a similar manner is unknown at present.

Obatoclax induced dramatic ultra-structural changes that appeared to be dependent upon Atg7; morphologically, the pattern of vacuolation was not typical for autophagy, however, within this background of inclusion bodies there was evidence of mitochondrial engulfment and autophagosome formation. We propose that these ultra-structural changes most likely reflect a direct effect of obatoclax that is independent of both the apoptosis and autophagy machinery, but could contribute to cell fate. Cells with either de novo log-fold resistance to obatoclax, or selected for resistance to obatoclax, exhibited marked suppression of apoptosis. ENU-selected H460 cells (H460-ENU) did not exhibit significant alterations in their BCL-2 family expression. This is the first study to examine the phenotype of isogenic cells selected for obatoclax resistance. However, apoptosis was suppressed by an unknown mechanism not involving loss of BAX and/or BAK expression. Acquisition of apoptosis block suggests that this process is important in determining cell fate, and is supported by the finding that, although BAX/BAK silencing in $\mathrm{H} 460$ cells did not 
abolish the loss of clonogenic survival associated with obatoclax, it reduced apoptosis sensitivity significantly. Similarly, in $\mathrm{H} 727$ cells, resistance was associated with a block in apoptosis. With respect to autophagy, resistant cells reduced but did not abolish LC3 processing. H727 cells also displayed cytoplasmic vacuolation following obatoclax treatment; however, this was not as extensive or dramatic as observed in $\mathrm{H} 1975$ cells. The question of whether H460-ENU cells exhibit cytoplasmic vacuolation in response to obatoclax treatment is currently being addressed. To establish whether cell death occurred through redundant pathways involving apoptosis or autophagy, silencing of Atg7 in BAX/BAK DKO MEFs was conducted. Despite partial rescue by knockdown of Atg7, obatoclax still exhibited toxicity irrespective of loss of these two pathways. We conclude that cell death, and importantly the mechanisms underlying resistance are likely to involve the alteration of genes outside of either the autophagy or apoptosis pathways.

\section{Materials and Methods}

Reagents. Obatoclax mesylate (GX15-070) was provided by GeminX Pharmaceuticals (Montreal, Canada). Obatoclax powder was dissolved in DMSO to a concentration of $5 \mathrm{mM}$, aliquoted and stored at $-20^{\circ} \mathrm{C}$. Recombinant human TRAIL was purchased from Calbiochem (San Diego, CA, USA). TRAIL was dissolved in sterile PBS/BSA $0.1 \%$ to a concentration of $20 \mu \mathrm{g} / \mathrm{ml}$, aliquoted and stored at $-80^{\circ} \mathrm{C}$. ENU was purchased from Sigma-Aldrich (St. Louis, MO, USA) and dissolved in DMSO to a concentration of $50 \mathrm{mg} / \mathrm{ml}$, aliquoted and stored at $-80^{\circ} \mathrm{C}$.

Cell lines and culture. All cells were maintained in $5 \% \mathrm{CO}_{2}$ at $37^{\circ} \mathrm{C}$. $\mathrm{H} 1975$ and $\mathrm{H} 460$ non-small-cell lung cancer (NSCLC) cells were maintained in Roswell Park Memorial Institute (RPMI) 1640 medium supplemented with 10\% fetal bovine serum and $50 \mu \mathrm{g} / \mathrm{ml}$ penicillin/streptomycin (all supplied by Life Technologies Inc., Paisley, Scotland). $\mathrm{H} 460^{\text {shBAX/BAK }}$ and $\mathrm{H} 460^{\text {shNT/NT }}$ cells were maintained in RPMI as described above, supplemented with $2 \mu \mathrm{g} / \mathrm{ml}$ puromycin and $400 \mu \mathrm{g} / \mathrm{ml} \mathrm{G} 418$ (both from Sigma-Aldrich). H727 NSCLC cells were maintained in Dulbecco's Modified Eagle Medium (DMEM) supplemented with $10 \%$ fetal bovine serum, $1 \mathrm{mM}$ sodium pyruvate and $50 \mu \mathrm{g} / \mathrm{ml}$ penicillin/streptomycin (all supplied by Life Technology Inc.). BAX/BAK double-knockout mouse embryonic fibroblasts (DKO MEFs) and their WT controls were a kind gift from Dr. Scott Oakes (University of California, San Francisco, CA, USA). WT and DKO MEFs were maintained in Iscove's Modified Dulbecco's Medium (IMDM) supplemented with $10 \%$ fetal bovine serum, $2 \mathrm{mM}$ L-glutamine, $0.1 \mathrm{mM}$ non-essential amino acids and $50 \mu \mathrm{g} / \mathrm{ml}$ penicillin/streptomycin (all from Life Technology Inc.). Atg7 WT and Atg $7^{-1-}$ MEFs were a kind gift from Dr. Masaaki Komatsu (The Tokyo Metropolitan Institute Medical Science, Tokyo, Japan). Atg7 WT and Atg $7^{-1-}$ MEFs were maintained in DMEM supplemented with $10 \%$ fetal bovine serum, $1 \mathrm{mM}$ sodium pyruvate, $0.1 \mathrm{mM}$ non-essential amino acids and $50 \mu \mathrm{g} / \mathrm{ml}$ penicillin/streptomycin (all from Life Technology Inc.)

Immunoblot analysis. When analyzing phosphoproteins, cells were scraped into ice-cold PBS supplemented with $1 \mathrm{mM} \mathrm{Na}_{3} \mathrm{VO}_{4}$, otherwise cells were scraped into media and pelleted by centrifugation at 1500 r.c.f at $4^{\circ} \mathrm{C}$ for $5 \mathrm{~min}$. Whole-cell lysates were obtained by snap freezing cells in RIPA lysis buffer $(50 \mathrm{mM}$ Tris (pH7.4), $150 \mathrm{mM} \mathrm{NaCl}, 5 \mathrm{mM}$ EDTA, $1 \%$ Triton X, 0.1\% SDS and one mini complete protease inhibitor tablet per $10 \mathrm{ml}$ (Roche Diagnostics, Indianapolis, IN, USA)) and defrosting frozen lysates on ice. When analysing phosphoproteins, RIPA was further supplemented with $1 \mathrm{mM} \mathrm{Na}_{3} \mathrm{VO}_{4}$ and $1 \mathrm{mM} \mathrm{NaF}$. Insoluble cell debris was removed from cell lysates by centrifugation at 13000 r.p.m for $15 \mathrm{~min}$ at $4{ }^{\circ} \mathrm{C}$. Samples were resolved by SDS-PAGE on $12 \%$ gels, transferred to nitrocellulose membranes and immunoblotted with the indicated primary antibodies. Goat antirabbit and goat anti-mouse horseradish peroxidise-conjugated secondary antibodies (Dako UK Ltd., Cambridgeshire, UK) were used in conjunction with appropriate primary antibodies. Bound antibodies were visualized using Amersham $\mathrm{ECL}$ plus chemiluminescent reagents (GE Healthcare Life Sciences, Buckinghamshire, UK) and Fuji-RX X-ray film (Fuji, Bedfordshire, UK). Rabbit primary antibodies used were those raised against cleaved caspase 9, cleaved caspase 3, LC3B, beclin-1, Atg5, Atg7, BAX, BAK and phospho S6 kinase (thr389) (all from Cell Signaling Technology Inc., Danvers, MA, USA), BAK N-terminus (Millipore, Billerica, MA, USA) and $\alpha$-tubulin (Abcam, Cambridge, MA, USA). Mouse primary antibodies used were those raised against PARP (eBiosciences, San Diego, CA, USA), SMAC and Cytochrome $c$ (both Calbiochem), GAPDH and VDAC (both Abcam), and $\beta$-actin (Sigma-Aldrich).

Immunoprecipitation. $\mathrm{H} 460$ cells were treated with obatoclax for 6, 24 and $48 \mathrm{~h}$. The cells were then harvested, washed in ice-cold PBS and lysed with NP-40 whole-cell lysis buffer $(150 \mathrm{mM} \mathrm{NaCl}, 50 \mathrm{mM}$ TrisHcl pH8, $5 \mathrm{mM}$ EDTA pH8, $1 \% \mathrm{NP} 40,2 \mathrm{mM}$ DTT, $1 \mathrm{mM}$ PMSF, $1 \mu \mathrm{g} / \mathrm{ml}$ pepstatin A, $1 \mu \mathrm{g} / \mathrm{ml}$ aprotinin, $2 \mathrm{mg} / \mathrm{ml}$ leupeptin and $1 \mathrm{mM}$ Benzamidine). Immunoprecipitation assays were carried out using $500 \mu \mathrm{g}$ of protein and either $1 \mu \mathrm{g}$ of murine $\alpha$-BAK antibody (BD Biosciences, Franklin Lakes, NJ, USA) or a murine IgG isotype control antibody (Dako, Glostrup, Denmark). Lysates were incubated at $4^{\circ} \mathrm{C}$ overnight with $20 \mu$ packed volume protein-G agarose beads (Sigma-Aldrich). Beads and bound immuno-complexes were spun down at low speed and the supernatant removed and then washed three times with $0.5 \mathrm{ml} \mathrm{IP}$ wash buffer (20 mM Hepes pH7.9, $75 \mathrm{mM} \mathrm{KCL}$ or $150 \mathrm{mM} \mathrm{KCl}$, $2.5 \mathrm{mM} \mathrm{MgCl}_{2}, 0.1 \%$ NP-40, $1 \mathrm{mM}$ DTT, $1 \mathrm{mM} \mathrm{PMSF}, 1 \mu \mathrm{g} / \mathrm{ml}$ pepstatin A, $1 \mu \mathrm{g} / \mathrm{ml}$ aprotinin, $2 \mathrm{mg} / \mathrm{ml}$ leupeptin and $1 \mathrm{mM}$ Benzamidine). Immunoprecipitated proteins were eluted with $30 \mu$ lof SDS sample buffer and heated at $95^{\circ} \mathrm{C}$ for $5 \mathrm{~min}$. A volume of $15 \mu \mathrm{l}$ of the eluted samples was separated by SDS-PAGE and immunoblotted with $\alpha-M C L-1$ antibody (Cell Signaling Technology Inc.).

Densitometry analysis. Densitometry analysis of western blots was carried out using ImageJ public domain image processing and analysis software.

ATP luminescent viability assay. The viability of cells on the basis of ATP levels was determined using ViaLight plus cell proliferation and cytotoxicity bioassay kit (Lonza Group Ltd., Basel, Switzerland). Analysis was carried out according to the manufacturer's instructions.

Adenylate kinase luminescent cytotoxicity assay. The level of adenylate kinase release from cells was used as a measure of cytotoxicity. Adenylate kinase release was measured using ToxiLight non-destructive cytotoxicity bioassay kit (Lonza Group Ltd., Basel, Switzerland). Analysis was carried out according to the manufacturer's instructions.

Cell proliferation kinetics. Cells were seeded in 6-well plates and drugged at indicted doses. Cells were then monitored using the INCUCYTE live cell imaging system (Essen BioScience, Ann Arbor, MI, USA). The INCUCYTE live cell imaging system was placed in a cell culture incubator operated at $37^{\circ} \mathrm{C}$ and $5 \% \mathrm{CO}_{2}$. Images were acquired every $3 \mathrm{~h}$ for a period of 7 days. A total of 16 user-defined data points were used to calculate cell confluency over each well in a 6-well plate. Cell confluency was determined using calculations derived from phase-contrast images. This data was condensed using algorithms into quantified metrics to obtain kinetic proliferation curves.

Clonogenic assays. Cells were plated into 24-well plates at single-cell density, followed by treatment with indicated doses of obatoclax for $24 \mathrm{~h}$. Medium was then replaced and cells were allowed to grow until untreated control wells had formed sufficient colonies.

Isolation of mitochondrial and cytosolic fractions. Following specified treatment periods harvested cells were incubated on ice for $15 \mathrm{~min}$, centrifuged at 1500 r.c.f $\times 5 \mathrm{~min}$ at $4^{\circ} \mathrm{C}$ and washed in mitochondrial isolation buffer (MIB) (200 mM Mannitol, $70 \mathrm{mM}$ Sucrose, $1 \mathrm{mM}$ EGTA, $10 \mathrm{mM}$ HEPES, $0.5 \mathrm{mg} / \mathrm{ml}$ $\mathrm{BSA}$, and pH7.4). Cells were resuspended in MIB and homogenized using a dounce homogenizer. The resulting homogenate was centrifuged at 800 r.c. $\times 5 \mathrm{~min}$ at $4^{\circ} \mathrm{C}$. Supernatants were removed and centrifuged at $10000 \mathrm{r}$.c. $\times 10 \mathrm{~min}$ at $4^{\circ} \mathrm{C}$. The resulting pellet was the mitochondrial fraction and supernatant used as the cytosolic fraction.

Determination of BAK conformation by proteolysis. Isolated mitochondria were resuspended in mitochondrial respiration buffer (MRB) (125 mM KCl, $5 \mathrm{mM}$ HEPES, $1 \mathrm{mM}$ EGTA, $1 \mathrm{mM} \mathrm{KHPO}$, $2.5 \mathrm{mM} \mathrm{MgCl}_{2}, 0.4 \%$ BSA, $7 \mathrm{mM}$ Succinate, and pH 7.4) and incubated with $125 \mu \mathrm{g} / \mathrm{ml}$ trypsin (GIBCO, Invitrogen, Carlsbad, CA, USA) on ice for $20 \mathrm{~min}$. Trypsin digestion was 
subsequently stopped using trypsin neutralization solution (Cambrex, East Rutherford, NJ, USA) and mitochondria pelleted by centrifugation at 10000 r.c.f $\times 10 \mathrm{~min}$ at $4^{\circ} \mathrm{C}$ and lysed in RIPA buffer.

SiRNA transfections. Pre-designed siRNAs were purchased for beclin-1, Atg5 and Atg7 (Qiagen, Germantown, MD, USA). As control siRNA, ON-TARGETplus non-targeting pool was purchased from Dharmacon (Lafayette, CO, USA). siRNA transfections were performed using DharmaFect 1 transfection reagent (Dharmacon) according to the manufacturer's instructions.

shRNA transfections and creation of stable cell lines. Pre-designed shRNA plasmids targeting BAX, BAK and BECLN1 were purchased from SA Biosciences (Frederick, MD, USA). H460 NSCLC cells were stably transfected with each of four different sequences using FuGene 6 transfection reagent (Roche Diagnostics). Transfected cells were put through two rounds of selection using appropriate antibiotic (puromycin $2 \mu \mathrm{g} / \mathrm{ml}, \mathrm{G} 418400 \mu \mathrm{g} / \mathrm{ml}$ ) to select multiple stable clones. Clones judged to have best knockdown were taken forward for analysis. For double transfection of BAX and BAK, cells stably expressing shRNA-targeting BAX were re-transfected with shRNA-targeting BAK and clones expressing stable knockdown of both BAX and BAK were selected.

hVps34-specific activity. Cells were cultured to $80-90 \%$ confluency then washed three times in PBS before depriving them of amino acids for 0 and $2 \mathrm{~h}$ in Earle's Balanced Salt Solution (EBSS) (Life Technology Inc.). Following lysis, cell extracts were clarified by centrifugation and then subjected to immunoprecipitation with anti-hVps34 antibody. Immunocomplexes were assayed for hVps34 lipidkinase activity with Ptdlns substrate and Mn2 $+-\left({ }^{32} \mathrm{P}-\gamma\right.$-ATP). Lipid products were visualized by exposure of TLC plates to a phosphor screen, read using a Fuji FLA7000 and quantied using multi-gauge software. Duplicate immunoprecipitations were resolved by SDS-PAGE and immunoblotted for hVps34 and beclin-1. hVps34 activity was expressed as specific activity after normalizing to the amount of immunoprecipitated hVps34 detected by immunoblotting.

Transmission electron microscopy. Following treatment with obatoclax, cells were trypsinized and fixed in TEM fixative (4\% paraformaldehyde, $2.5 \%$ glutaraldehyde made up in $0.1 \mathrm{M}$ sodium cacodylate buffer). Fixation was for $4 \mathrm{~h}$ at $37^{\circ} \mathrm{C}$ after which excess fixative was washed out in cacodylate buffer $(4-6 \mathrm{~h})$ before samples were post-fixed $(1 \mathrm{~h})$ in $1 \%$ aq osmium tetroxide then dehydrated in graded ethanol solutions before embedment in SPI-PON 812 epoxy resin (SPI chemicals Ltd., West Chester, PA, USA).

Selection of obatoclax-resistant cells. Cells resistant to obatoclax were selected using ENU to induce mutagenesis. H460 NSCLC cells were seeded into T80 tissue culture flasks (Nunc, Life Technologies Inc.) at 50-60\% confluency. Cells were then exposed to $75 \mu \mathrm{g} / \mathrm{ml}$ ENU (Sigma-Aldrich) for $24 \mathrm{~h}$. Following ENU exposure, cells were washed three times with RPMI and re-seeded in complete growth medium and allowed to proliferate for 1 week. After 1 week, cells were seeded into 96-well plates at 8000 cells per well and treated with a range of obatoclax doses. The concentrations of obatoclax used were $0.3,1,3$, and $10 \mu \mathrm{M}$. Wells were observed for growth by visual inspection for 4-8weeks. When growth occurred cells were transferred to 24-well plates and expanded in the presence of the corresponding dose of obatoclax.

Statistical analysis. All data represent at least three independent experiments and are expressed as mean \pm S.D. or mean \pm S.E. as stated. Differences between groups were compared using Student's t-test where appropriate $\left({ }^{*} P\right.$-value $=0.01-0.05, \quad{ }^{*} P$-value $=0.001-0.01, \quad{ }^{* * *} P$-value $=$ $<0.001)$. EC 50 values were determined using non-linear regression on GraphPad Prism 5 (GraphPad, La Jolla, CA, USA).

\section{Conflict of interest}

The authors declare no conflict of interest.

Acknowledgements. We thank Drs. Gordon Shore and Pierre Beauparlant (Gemin X) for provision of obatoclax, Dr. Scott Oakes (University of California, San Francisco, CA, USA) for providing BAX/BAK DKO MEFs, and Dr. Masaaki Komatsu (The Tokyo Metropolitan Institute Medical Science, Tokyo, Japan) for providing Atg7 knockout MEFs. This work was supported by Cancer Research UK, DEL studentship and the Health and Social Care Research and Development Office, Belfast, Northern Ireland. Dr. Fennell is a recipient of a Cancer Research Clinician Scientist Fellowship.

1. Hanahan D, Weinberg RA. The hallmarks of cancer. Cell 2000; 100: $57-70$.

2. Wei MC, Zong WX, Cheng EH, Lindsten T, Panoutsakopoulou V, Ross AJ et al. Proapoptotic BAX and BAK: a requisite gateway to mitochondrial dysfunction and death. Science 2001; 292: 727-730.

3. Li P, Nijhawan D, Budihardjo I, Srinivasula SM, Ahmad M, Alnemri ES et al. Cytochrome c and dATP-dependent formation of Apaf- $1 /$ caspase- 9 complex initiates an apoptotic protease cascade. Cell 1997; 91: 479-489.

4. Zou H, Henzel WJ, Liu X, Lutschg A, Wang X. Apaf-1, a human protein homologous to $C$. elegans CED-4, participates in cytochrome c-dependent activation of caspase-3. Cell 1997; 90: 405-413.

5. Zou H, Li Y, Liu X, Wang X. An APAF-1.cytochrome c multimeric complex is a functional apoptosome that activates procaspase-9. J Biol Chem 1999; 274: 11549-11556.

6. Jiang $X$, Wang $X$. Cytochrome $c$ promotes caspase- 9 activation by inducing nucleotide binding to Apaf-1. J Biol Chem 2000; 275: 31199-31203.

7. Lakhani SA, Masud A, Kuida K, Porter GA, Booth CJ, Mehal WZ et al. Caspases 3 and 7: key mediators of mitochondrial events of apoptosis. Science 2006; 311: 847-851.

8. Kuwana T, Bouchier-Hayes L, Chipuk JE, Bonzon C, Sullivan BA, Green DR et al. BH3 domains of $\mathrm{BH} 3$-only proteins differentially regulate Bax-mediated mitochondrial membrane permeabilization both directly and indirectly. Mol Cell 2005; 17: 525-535.

9. Wei MC, Lindsten T, Mootha VK, Weiler S, Gross A, Ashiya M et al. tBID, a membranetargeted death ligand, oligomerizes BAK to release cytochrome c. Genes Dev 2000; 14 : 2060-2071.

10. Beroukhim R, Mermel $\mathrm{CH}$, Porter D, Wei G, Raychaudhuri S, Donovan J et al. The landscape of somatic copy-number alteration across human cancers. Nature 2010; 463 : 899-905.

11. Letai AG. Diagnosing and exploiting cancer's addiction to blocks in apoptosis. Nat Rev Cancer 2008; 8: 121-132.

12. Zhang L, Ming L, Yu J. BH3 mimetics to improve cancer therapy; mechanisms and examples. Drug Resist Updat 2007; 10: 207-217.

13. Oltersdorf T, Elmore SW, Shoemaker AR, Armstrong RC, Augeri DJ, Belli BA et al. An inhibitor of Bcl-2 family proteins induces regression of solid tumours. Nature 2005; 435 677-681.

14. van Delft MF, Wei AH, Mason KD, Vandenberg CJ, Chen L, Czabotar PE et al. The BH3 mimetic ABT-737 targets selective Bcl-2 proteins and efficiently induces apoptosis via Bak/ Bax if Mcl-1 is neutralized. Cancer Cell 2006; 10: 389-399.

15. Tahir SK, Yang X, Anderson MG, Morgan-Lappe SE, Sarthy AV, Chen J et al. Influence of Bcl-2 family members on the cellular response of small-cell lung cancer cell lines to ABT737. Cancer Res 2007; 67: 1176-1183.

16. Shore GC, Viallet J. Modulating the bcl-2 family of apoptosis suppressors for potential therapeutic benefit in cancer. Hematology Am Soc Hematol Educ Program 2005; 2005: 226-230.

17. Zhai $D$, Jin $C$, Satterthwait AC, Reed JC. Comparison of chemical inhibitors of antiapoptotic Bcl-2-family proteins. Cell Death Differ 2006; 13: 1419-1421.

18. Nguyen M, Marcellus RC, Roulston A, Watson M, Serfass L, Murthy Madiraju SR et al. Small molecule obatoclax (GX15-070) antagonizes MCL-1 and overcomes MCL-1 mediated resistance to apoptosis. Proc Natl Acad Sci USA 2007; 104: 19512-19517.

19. Konopleva M, Watt J, Contractor R, Tsao T, Harris D, Estrov Z et al. Mechanisms of antileukemic activity of the novel Bcl-2 homology domain-3 mimetic GX15-070 (obatoclax). Cancer Res 2008; 68: 3413-3420.

20. Mott JL, Bronk SF, Mesa RA, Kaufmann SH, Gores GJ. BH3-only protein mimetic obatoclax sensitizes cholangiocarcinoma cells to Apo2L/TRAIL-induced apoptosis. Mol Cancer Ther 2008; 7: 2339-2347.

21. Perez-Galan P, Roue G, Villamor N, Campo E, Colomer D. The BH3-mimetic GX15-070 synergizes with bortezomib in mantle cell lymphoma by enhancing Noxa-mediated activation of Bak. Blood 2007; 109: 4441-4449.

22. Trudel S, Li ZH, Rauw J, Tiedemann RE, Wen XY, Stewart AK. Preclinical studies of the pan-Bcl inhibitor obatoclax (GX015-070) in multiple myeloma. Blood 2007; 109: 5430-5438.

23. Huang S, Okumura K, Sinicrope FA. BH3 mimetic obatoclax enhances TRAIL-mediated apoptosis in human pancreatic cancer cells. Clin Cancer Res 2009; 15: 150-159.

24. Vogler M, Weber K, Dinsdale D, Schmitz I, Schulze-Osthoff K, Dyer MJ et al. Different forms of cell death induced by putative BCL2 inhibitors. Cell Death Differ 2009; 16: $1030-1039$

25. Pan J, Cheng C, Verstovsek S, Chen Q, Jin Y, Cao Q. The BH3-mimetic GX15-070 induces autophagy, potentiates the cytotoxicity of carboplatin and 5-fluorouracil in esophageal carcinoma cells. Cancer Lett 2010; 293: 167-174.

26. Bonapace L, Bornhauser BC, Schmitz M, Cario G, Ziegler U, Niggli FK et al. Induction of autophagy-dependent necroptosis is required for childhood acute lymphoblastic leukemia cells to overcome glucocorticoid resistance. J Clin Invest 2010; 120: 1310-1323. 
27. Martin AP, Mitchell C, Rahmani M, Nephew KP, Grant S, Dent P. Inhibition of MCL-1 enhances lapatinib toxicity and overcomes lapatinib resistance via BAK-dependent autophagy. Cancer Biol Ther 2009; 8: 2084-2096.

28. Martin AP, Park MA, Mitchell C, Walker T, Rahmani M, Thorburn A et al. BCL-2 family inhibitors enhance histone deacetylase inhibitor and sorafenib lethality via autophagy and overcome blockade of the extrinsic pathway to facilitate killing. Mol Pharmacol 2009; 76: 327-341.

29. Pattingre S, Tassa A, Qu X, Garuti R, Liang XH, Mizushima N et al. Bcl-2 antiapoptotic proteins inhibit Beclin 1-dependent autophagy. Cell 2005; 122: 927-939.

30. Maiuri MC, Criollo A, Tasdemir E, Vicencio JM, Tajeddine N, Hickman JA et al. BH3-only proteins and $\mathrm{BH} 3$ mimetics induce autophagy by competitively disrupting the interaction between Beclin 1 and Bcl-2/Bcl-X(L). Autophagy 2007; 3: 374-376.

31. Erlich S, Mizrachy L, Segev O, Lindenboim L, Zmira O, Adi-Harel S et al. Differential interactions between Beclin 1 and Bcl-2 family members. Autophagy 2007; 3: 561-568.

32. Levine B, Sinha S, Kroemer G. Bcl-2 family members: dual regulators of apoptosis and autophagy. Autophagy 2008; 4: 600-606.

33. Qu X, Yu J, Bhagat G, Furuya N, Hibshoosh $\mathrm{H}$, Troxel A et al. Promotion of tumorigenesis by heterozygous disruption of the beclin 1 autophagy gene. J Clin Invest 2003; 112 $1809-1820$

34. Yue Z, Jin S, Yang C, Levine AJ, Heintz N. Beclin 1, an autophagy gene essential for early embryonic development, is a haploinsufficient tumor suppressor. Proc Natl Acad Sci USA 2003; 100: 15077-15082.
35. Pattingre S, Levine B. Bcl-2 inhibition of autophagy: a new route to cancer? Cancer Res 2006; 66: 2885-2888

36. Shimizu S, Kanaseki T, Mizushima N, Mizuta T, Arakawa-Kobayashi S, Thompson CB et al. Role of $\mathrm{Bcl}-2$ family proteins in a non-apoptotic programmed cell death dependent on autophagy genes. Nat Cell Biol 2004; 6: 1221-1228.

37. Gobeil S, Boucher CC, Nadeau D, Poirier GG. Characterization of the necrotic cleavage of poly(ADP-ribose) polymerase (PARP-1): implication of lysosomal proteases. Cell Death Differ 2001; 8: 588-594.

38. Gao P, Bauvy C, Souquere S, Tonelli G, Liu L, Zhu Y et al. The BH3-mimetic gossypo induces both beclin 1-dependent and beclin 1-independent cytoprotective autophagy in cancer cells. J Biol Chem 2010.

39. Zhu JH, Horbinski C, Guo F, Watkins S, Uchiyama Y, Chu CT. Regulation of autophagy by extracellular signal-regulated protein kinases during 1-methyl-4-phenylpyridinium-induced cell death. Am J Pathol 2007; 170: 75-86.

(c)

Cell Death and Disease is an open-access journal published by Nature Publishing Group. This work is licensed under the Creative Commons Attribution-Noncommercial-No Derivative Works 3.0 Unported License. To view a copy of this license, visit http://creativecommons.org/licenses/by-nc-nd/3.0/ 